\title{
EI ROL DE LOS MOLUSCOS EN LAS POBLACIONES PREHISPÁNICAS DE URUGUAY
}

\section{THE ROLE OF MOLLUSCS IN PRE-HISPANIC POPULATIONS OF URUGUAY}

\author{
Andrés Gascue1, Fabrizio Scarabino2, Noelia Bortolotto ${ }^{3}$, \\ Cristhian Clavijo ${ }^{4}$, Irina Capdepont ${ }^{5}$
}

${ }^{1}$ Centro Universitario Regional del Este, Rutas 9 y 15. Rocha, Uruguay. andresgascue@gmail.com

${ }_{2}$ Centro Universitario Regional del Este. Museo Nacional de Historia Natural, Miguelete 1825. C. C. 399 - 11.000. Montevideo, Uruguay. mycetopoda@gmail.com

${ }^{3}$ Centro Universitario Regional del Este. Instituto Nacional de Antropología y

Pensamiento Latinoamericano, 3 de febrero 1370. Buenos Aires, Argentina. noeliabortolotto@gmail.com.

${ }^{4}$ Centro Universitario Regional del Este. Museo Nacional de Historia Natural, Miguelete 1825. C. C. 399 - 11.000. Montevideo, Uruguay.mycetopoda@gmail.com.

${ }^{5}$ Centro Universitario Regional del Este Facultad de Ciencias - Laboratorio de Estudios del Cuaternario (MEC-UNCIEP, IECA), Iguá 4225. Montevideo, Uruguay. i.capdepont@gmail.com

Presentado: 10/11/2018 - Aceptado: 27/03/2019

\section{Resumen}

La ocurrencia de moluscos en contextos arqueológicos es habitual, debido a la importancia de los mismos para la alimentación, para ámbitos rituales y simbólicos, para la fabricación de instrumentos y como material constructivo. Se sintetizan aquí los datos referentes al manejo diferencial de materiales malacológicos realizado por las poblaciones cazadoras-recolectoras prehispánicas que ocuparon las regiones Este, Centro-Sur y Oeste de Uruguay durante el Holoceno tardío, con especial referencia a la identificación taxonómica y a los usos inferidos. Se realizó un relevamiento bibliográfico exhaustivo y de materiales presentes en algunos acervos públicos, sumando información inédita, para profundizar en los modos de uso y procesos de intercambio intercultural regional. Los moluscos se asocian principalmente a los aspectos simbólicos (ornamentales y funerarios) de estas culturas y a actividades económicas vinculadas al consumo alimentario y producción de artefactos utilitarios. Desde el punto de vista contextual se asocian a espacios de actividades mayoritariamente domésticas, así como a otros que conjugan actividades diversas (domésticas, constructivas y/o funerarias) ubicados entre ca. $3300{ }^{14} \mathrm{C}$ años $A P$ y $500{ }^{14} \mathrm{C}$ años $A P$.

Palabras clave: Arqueomalacología, cazadores-recolectores, Holoceno tardío, simbolismo, tecno-economía

\footnotetext{
Abstract

The presence of molluscs in archaeological contexts is usual given their importance for food and within the ritualistic and symbolic spheres as well for tool making and as constructive material. We summarize the evidences about differential use of mollusks made by hunther-
} 
gatherers that inhabited the fluvial littoral, estuarine and oceanic shores of Uruguay during late Holocene. Special attention was paid to taxonomic attribution and inferred uses. We made an exhaustive bibliographic survey, as well as the analysis of material present in some public collections, focusing on the ways of use and processes of intercultural regional interchange. The molluscs are mainly associated to symbolic aspects (ornamental and funerary) of these cultures and, to economic ones associated to food consumption and production of utilitarian artefacts. From the contextual point of view, they are associated with spaces of mostly domestic activities, as well as with others that combine diverse activities (domestic, constructive and / or funerary) ranging from ca. $3300{ }^{14} \mathrm{C}$ years $B P$ to $500{ }^{14} \mathrm{C}$ years $B P$.

Key words: Archaeoemalacology, hunter-gatherers, late Holocene, symbolism, technoeconomy.

\section{Introducción}

La Arqueomalacología, entendida como la rama de la Arqueozoología que se ocupa del estudio de los restos de moluscos en contextos arqueológicos comienza a desarrollarse a partir del siglo XIX en respuesta a la atención prestada a las importantes concentraciones de moluscos de origen antrópico y cronología prehistórica presentes principalmente en las costas noroccidentales europeas (Bejega et al. 2010). La ocurrencia de moluscos en contextos arqueológicos tanto prehistóricos como históricos es habitual, debido a su importancia para la alimentación, en ámbitos rituales y simbólicos (incluyendo los ornamentales), así como en la fabricación de instrumentos y en su uso como material constructivo. La mayoría de estos aspectos se registran desde hace ca. 500.000 años por parte de Homo erectus, y están bien desarrolladas en Homo neanderthalensis y en nuestra especie (e.g. Balbo et al. 2011, Bejega et al. 2010, CortésSánchez et al. 2011, Joordens 2015, Trubitt 2003, Wagner et al. 2011).

A nivel regional se han realizado esfuerzos por sintetizar e interpretar la información arqueomalacológica existente. Para la Región Pampeana (Argentina) se ha destacado el uso simbólico de los moluscos marinos (incluyendo modificaciones o no) y en menor medida usos tecnológicos, no registrándose vinculación clara de dicha fauna con la dieta humana (Acosta et al. 2017, Bonomo 2007, Bonomo y Aguirre 2009). Para la cuenca baja del río Paraná y cuenca media y baja del río Uruguay el uso de especies dulceacuícolas (principalmente almejas del género Diplodon) fue comparativamente más importante en términos de abundancia. En este sentido, se han registrado en algunos sitios acumulaciones caracterizadas como concheros (e.g. Loponte y Acosta 2017). Asimismo, fueron considerados una de las principales materias primas utilizadas para la elaboración de adornos (Acosta et al. 2015).

Los primeros registros a nivel nacional datan de finales del siglo XIX a partir de los hallazgos de Diplodon sp. y Anodontites sp. realizados por Figueira (1892) en sitios arqueológicos ubicados en el litoral oeste de Uruguay, asociándolos a la subsistencia de grupos Chaná. El uso simbólico de los moluscos fue documentado por primera vez por Arechavaleta (1892). En relación a esqueletos indígenas encontrados en cerritos de San 
Luis, describe: "Debajo de las vértebras del cuello de uno de ellos encontramos un lecho de valvas de Unio charruanus [Diplodon sp.], y en otro varios Trochus [Agathistoma patagonicum] del mar oceánico." (Arechavaleta 1892: 104). También Doello-Jurado (1917) menciona el hallazgo de cuentas manufacturadas sobre caracoles del género Urosalpinx en sitios del delta del Paraná-Uruguay (isla Martín García), y posteriormente para el este de Uruguay en la localidad San Luis, departamento de Rocha (Doello-Jurado 1940). Hallazgos similares al mencionado han sido documentados en las provincias de Córdoba, San Luis, Mendoza, Santiago del Estero y Tucumán (Argentina). A partir de ello se comienza a interpretar contactos e intercambios interculturales a escala extra-regional, proponiéndose el litoral oceánico uruguayo como fuente de origen de los referidos caracoles (Doello-Jurado 1940).

La interacción entre la malacología y la arqueología en Uruguay durante los siglos XX y XXI ha sido muy limitada, restringiendo la documentación y la interpretación del registro arqueomalacológico. A su vez, el registro existente está relativamente subestimado y disperso; las pocas síntesis al respecto y numerosas referencias importantes para ambas disciplinas son bastante crípticas y han pasado desapercibidas en muchos casos. En este sentido, se destacan los trabajos de Bonino de Langguth (1961) y Olazarri (1975), así como las numerosas referencias realizadas por Maeso (1977). En los últimos 25 años se activaron a nivel nacional, a través de distintas iniciativas, estudios arqueomalacológicos (e.g. Beovide 2013, López Mazz 1995b, López Mazz et al. 1997, Mañosa 1995, Scarabino et al. 2016a, Villarmarzo 2010) pero aún persisten desafíos que son discutidos en este trabajo.

Desde un enfoque interdisciplinario, el presente trabajo sintetiza la información arqueomalacológica existente para Uruguay considerando también las limitaciones y sesgos que presenta la documentación relevada. La metodología implicó: una revisión bibliográfica exhaustiva y el relevamiento preliminar de colecciones e información inédita. El objetivo ha sido identificar y analizar el abanico de especies utilizadas por los grupos indígenas de Uruguay. También se atendió a la forma en que cada una de estas especies fue aprovechada, evaluando su peso en la economía cazadorarecolectora a nivel nacional, así como, su relación con los aspectos ideacionales de estas culturas. Para esto, se consideró la disponibilidad y hábitats de las especies objeto de explotación, para ahondar en los modos de utilización y los procesos de intercambio intercultural en el que estos materiales estuvieron insertos.

\section{Limitaciones y sesgos de la información}

De forma similar a lo referido para el registro arqueomalacológico de regiones vecinas (Bonomo 2007) las fuentes de información aquí utilizadas contienen numerosas limitaciones y sesgos que requieren su consideración particular. En muchos casos los registros arqueomalacológicos no han sido cuantificados, provienen de contextos superficiales y no todos cuentan con dataciones numéricas. Otras limitaciones se relacionan a la ausencia de identificaciones taxonómicas, donde los restos son catalogados como valvas de moluscos, caracoles, etc. (e.g. Gianotti et al. 2007, Guidón 1989, Maeso 1977, 
Tassé 1989, Toscano 1987) o a identificaciones erróneas que pudieron ser corregidas en este trabajo a partir de la existencia de fotografías incluidas en las publicaciones (e.g. Beovide y Lorenzo 2014, López Mazz 1995b). Otros trabajos carecen de imágenes (e.g. Bonino de Langguth 1961, Boretto 1969, Bracco 1992), lo que imposibilita corroborar la pertinencia de las identificaciones taxonómicas y contextos de hallazgo. En otros casos, por el contrario, solo se dispone de imágenes de los registros (Maruca Sosa 1957), donde para la localización espacial de los mismos se hace referencia a antiguos topónimos que engloban a amplias zonas y no a un sitio en particular.

Complementaria y particularmente en el caso de las colecciones relevadas (colección Maeso y colección Oliveras), destacamos la ausencia de datos contextuales, más allá de la adscripción a yacimientos arqueológicos concretos. En muchos casos, las colecciones no están fácilmente accesibles, al punto de resultar incierto la existencia de algunos materiales y por lo tanto la posibilidad de la verificación o ampliación de las identificaciones. Finalmente muchos moluscos, en particular los continentales, poseen escasa calcificación y/o fácil degradación in situ y ex situ (en campo, durante el transporte y almacenamiento en los reservorios) aspectos que deben ser atendidos en el futuro.

\section{Distribución espacial, cronológica y funcionalidad del registro arqueomalacológico uruguayo}

Los datos arqueológicos acerca de las ocupaciones humanas del litoral uruguayo (oceánico, estuarino y fluvial) muestran numerosos yacimientos atribuidos a grupos cazadores-recolectores donde los recursos malacológicos fueron aprovechados desde el punto de vista tecno-económico y simbólico durante el Holoceno tardío. Estas evidencias se distribuyen en los departamentos de Rocha, Maldonado, Canelones, Montevideo, San José, Soriano, Río Negro y Salto.

Moluscos con y sin modificaciones antrópicas han sido registrados en 27 sitios arqueológicos del litoral oceánico, estuarino y fluvial del territorio uruguayo algunos de los cuales cuentan con fechados numéricos (Figura 1; Tabla 1). Se han identificado un total de 35 especies de moluscos presentes en yacimientos arqueológicos. La malacofauna parece haber participado en distintas esferas de la cultura, siendo interpretada como: objeto de consumo alimenticio, materia prima para la confección de artefactos utilitarios y ornamentales, como elementos simbólicos asociados a prácticas funerarias, mientras que algunas especies fueron multifuncionales (Tablas 2-4). A nivel general, el $51,4 \%$ de las especies corresponden a gasterópodos, mientras que en el restante $48,6 \%$ se trata de bivalvos. En los registros dominan las especies de ambientes marinos (50,0\%), seguidas por las dulceacuícolas (23,5\%), estuarinas (17,6\%) y terrestres $(8,8 \%)$, sin existir exacta correlación con los ambientes o zonas en las que se emplazan los sitios. Esto último estaría indicando que varias especies fueron objeto de transporte desde sus áreas de captación. 
En la región Este los materiales malacológicos se vinculan a sitios costeros (e.g. Gascue et al. 2016a, López Mazz 1995b, Seijo 1930) y a estructuras monticulares (construcciones antrópicas en tierra) denominadas cerritos de indios (Bracco 1992, Cabrera et al. 200, Capdepont et al. 2016). Por su parte, en la región Centro-Sur (costa Río de la Plata) estos materiales se encuentran en sitios estrechamente vinculados a las paleolíneas de costa modeladas a partir del Holoceno medio (e.g. Beovide 2011, Beovide y Martínez 2014). En la región Oeste (litoral del Río Uruguay) se ubican en yacimientos emplazados sobre cordones litorales arenosos (e.g. Boretto 1969), albardones (e.g. Gascue et al. 2016b, Maeso 1977) y en sitios ubicados en las islas (e.g. Guidón 1989).

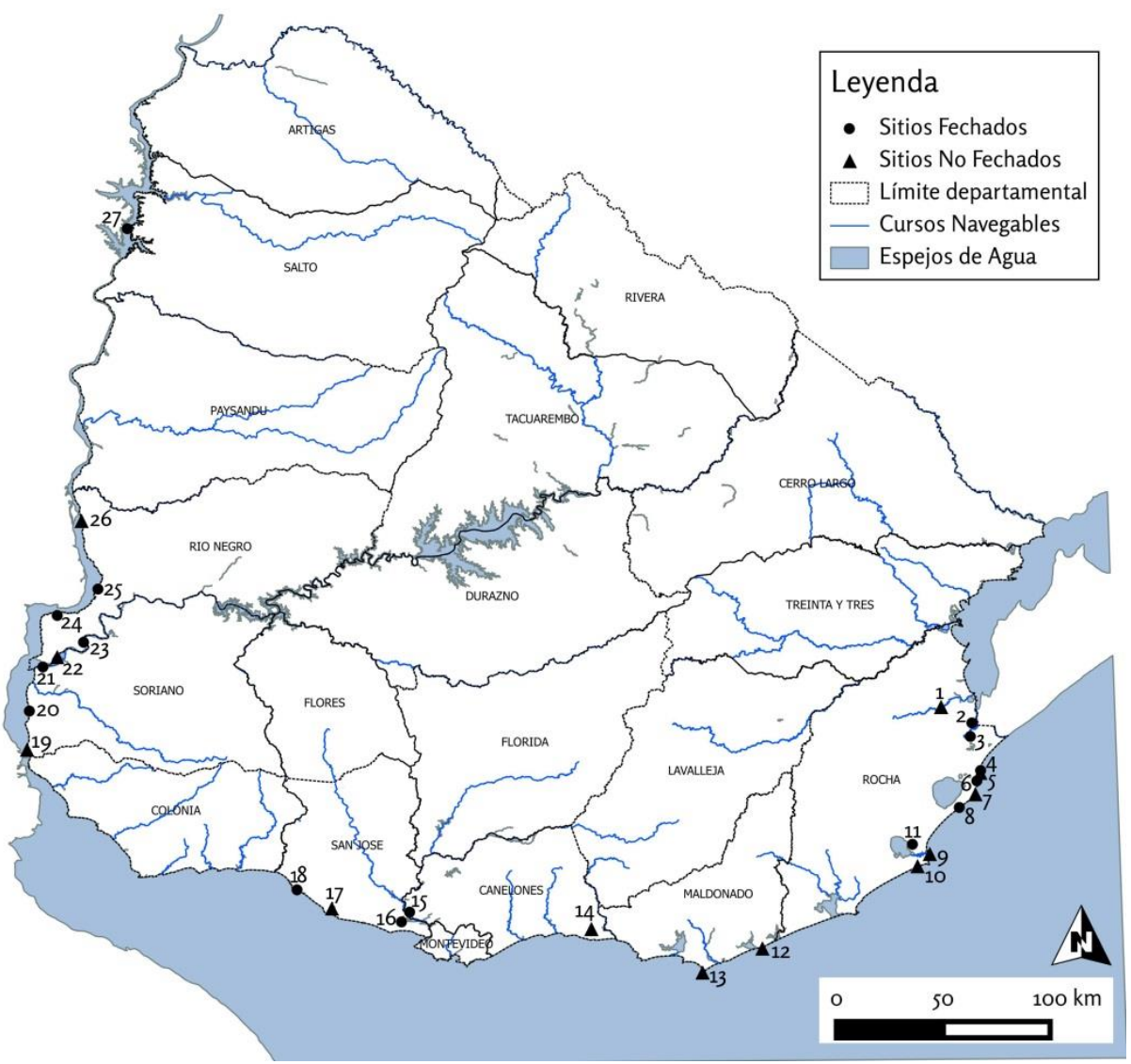

Figura 1: Sitios arqueológicos de Uruguay con presencia de moluscos; 1-San Luis; 2-CG14E01; 3CH2D01; 4-La Coronilla; 5-Cerro Verde; 6-La Moza; 7-Punta del Diablo; 8-La Esmeralda; 9-Cerro Buena Vista; 10-Cabo Polonio; 11-Guardia del Monte; 12-José Ignacio; 13-Punta del Este; 14-Piedras de Afilar; 15-Gambé; 16-Colonización; 17-Ao San Gregorio; 18-Arazatí/ Ao Pereira; 19-Punta Chaparro; 20-Cda Saldaña/Colonia Concordia; 21-La Blanqueada/Rincón de la Higuera; 22-Isla del Infante; 23-El Cerro; 24-Yaguareté; 25-La Yeguada; 26-Puerto Viejo; 27-Y58.

Los contextos arqueológicos donde se encuentran moluscos corresponden a espacios donde se han realizado actividades domésticas y otros donde se conjugan diversas actividades (constructivas, domésticas y/o funerarias) ubicados cronológicamente entre el ca. 3300 AP y 500 años AP (Tabla 1). En general los moluscos se presentan en bajas densidades, excepto por algunos concheros referidos para la costa atlántica y estuarina, así como las llamadas caracoleras del río Uruguay medio 
(estructuras que detallaremos más adelante). Sin embargo, se destaca en todas las zonas aquí referidas, una gran diversidad de especies provenientes de distintos ambientes (marino, dulceacuícola, terrestre y mixohalino).

\begin{tabular}{|c|c|c|c|c|c|}
\hline Región & Sitio & Tipo sitio & $\begin{array}{l}\text { Fechado sitio } \\
\left.\text { (años } \mathrm{C}^{14} \mathrm{AP}\right)\end{array}$ & $\begin{array}{l}\text { Material } \\
\text { Fechado }\end{array}$ & Fuente \\
\hline \multirow{7}{*}{$\begin{array}{c}\text { Este - } \\
\text { Costa Atlántica }\end{array}$} & 2 CG14E01 & Cerrito & $\begin{array}{c}1610 \pm 46- \\
220 \pm 50\end{array}$ & $\begin{array}{c}\text { H. sapiens } \\
\text { Carbón }\end{array}$ & Figueiro et al. 2017 \\
\hline & \multirow[t]{2}{*}{3 CH2D01 } & Cerrito A & $\begin{array}{c}2090 \pm 90 \\
1835 \pm 120 \\
1350 \pm 160 \\
400 \pm 50 \\
340 \pm 115\end{array}$ & Carbón & \multirow[t]{2}{*}{ Bracco et al. 2000} \\
\hline & & Cerrito B & $\begin{array}{c}2430 \pm 60 \\
2350 \pm 60 \\
1700 \pm 100 \\
1090 \pm 70 \\
\end{array}$ & Carbón & \\
\hline & 4 La Coronilla & $\begin{array}{l}\text { Costero - } \\
\text { Península }\end{array}$ & $2740 \pm 60$ & O. auricularia & López Mazz 1995 \\
\hline & 6 La Moza & $\begin{array}{l}\text { Costero - } \\
\text { Península }\end{array}$ & $2490 \pm 30$ & $\begin{array}{c}\text { Endocarpo } B . \\
\text { odorata }\end{array}$ & Gascue et al. 2016 \\
\hline & 8 La Esmeralda & $\begin{array}{c}\text { Costero - Arco } \\
\text { playa }\end{array}$ & $\begin{array}{l}3300 \pm 40 \\
3270 \pm 40 \\
3210 \pm 50 \\
3190 \pm 50 \\
3190 \pm 80 \\
3060 \pm 90 \\
3010 \pm 50 \\
2510 \pm 50 \\
2360 \pm 70 \\
1080 \pm 60 \\
1000 \pm 70 \\
\end{array}$ & $\begin{array}{c}\text { Carbón } \\
\text { Carbón } \\
\text { D. hanleyanus } \\
\text { Carbón } \\
\text { D. hanleyanus } \\
\text { Carbón } \\
\text { D. hanleyanus } \\
\text { D. hanleyanus } \\
\text { Carbón } \\
\text { D. hanleyanus } \\
\text { Carbón } \\
\end{array}$ & $\begin{array}{l}\text { Castiñeira et al. 2007; } \\
\text { Villarmarzo } 2010\end{array}$ \\
\hline & $\begin{array}{l}11 \text { Guardia del } \\
\text { Monte }\end{array}$ & $\begin{array}{l}\text { Planicie } \\
\text { Laguna }\end{array}$ & $<4600 \pm 60$ & $\begin{array}{c}\text { Moluscos } \\
\text { depósito } \\
\text { subyacente } \\
\end{array}$ & Capdepont et al. 2016 \\
\hline \multirow{3}{*}{$\begin{array}{l}\text { Centro Sur - } \\
\text { Costa Río de la } \\
\text { Plata }\end{array}$} & $\begin{array}{c}15 \\
\text { Colonización }\end{array}$ & $\begin{array}{c}\text { Conchero en } \\
\text { Paleocosta }+2,5 \\
\text { msnm }\end{array}$ & $2,310 \pm 60$ & $\begin{array}{l}\text { E. mactroides } \\
\text { depósito } \\
\text { subyacente }\end{array}$ & $\begin{array}{l}\text { Beovide y Malán } \\
\text { 2004;Beovide } 2009\end{array}$ \\
\hline & 16 Gambé & $\begin{array}{l}\text { Conchero en } \\
\text { cordón } \\
\text { arenoso+4,5 } \\
\text { msnm }\end{array}$ & $\begin{array}{l}2409 \pm 32 \\
2365 \pm 32\end{array}$ & E. mactroides & Beovide 2009 \\
\hline & 18 Arazatí & Arenal & $\begin{array}{l}895 \pm 27 \\
476 \pm 30 \\
\end{array}$ & $\begin{array}{l}\text { U. haneti } \\
\text { H. sapiens }\end{array}$ & Beovide et al. 2015b \\
\hline \multirow{6}{*}{$\begin{array}{l}\text { Oeste - Litoral } \\
\text { Río Uruguay }\end{array}$} & $\begin{array}{l}20 \text { Cañada } \\
\text { Saldaña }\end{array}$ & $\begin{array}{l}\text { Montículo } \\
\text { artificial }\end{array}$ & $\begin{array}{c}1840 \pm 100 \\
1780 \pm 70 \\
1710 \pm 110 \\
\end{array}$ & $\begin{array}{l}\text { H. sapiens } \\
\text { H. sapiens } \\
\text { Fauna nd } \\
\end{array}$ & $\begin{array}{c}\text { Maruca Sosa 1957; } \\
\text { Castillo } 2004\end{array}$ \\
\hline & $\begin{array}{c}21 \mathrm{La} \\
\text { Blanqueada }\end{array}$ & Albardón & $\begin{array}{l}1150 \pm 70 \\
1275 \pm 150 \\
1460 \pm 70 \mathrm{y} \\
1760 \pm 120 \\
\end{array}$ & $\begin{array}{c}\text { Carbón } \\
\text { Cerám. (TLD) } \\
\text { Carbón } \\
\text { Carbón } \\
\end{array}$ & Farías 2005 \\
\hline & 23 El Cerro & Albardón & $1910 \pm 50$ & H. sapiens & $\begin{array}{c}\text { Castillo 2004; Gascue } \\
\text { et al. 2016b }\end{array}$ \\
\hline & 24 Yaguareté & $\mathrm{Nd}$ & $1791 \pm 50$ & H. sapiens & $\begin{array}{c}\text { Col. } \\
\text { MMHNRN;AA104423 }\end{array}$ \\
\hline & 25 La Yeguada & $\begin{array}{l}\text { Cordón } \\
\text { arenoso }\end{array}$ & $\begin{array}{l}560 \pm 70 \\
510 \pm 45\end{array}$ & Carbón & $\begin{array}{c}\text { Castillo 2004; Loponte } \\
\text { et al. } 2016\end{array}$ \\
\hline & $27 \mathrm{Y}-58$ & $\begin{array}{c}\text { "Caracolera" 0- } \\
85 \mathrm{~cm} \text { prof }\end{array}$ & $\begin{array}{c}2420 \pm 80 \\
1140 \pm 100\end{array}$ & $\begin{array}{l}\text { H. sapiens } \\
\text { Carbón }\end{array}$ & $\begin{array}{c}\text { Guidón 1989; Díaz } \\
1977 \\
\end{array}$ \\
\hline
\end{tabular}

Tabla 1: Tipos de sitio y dataciones numéricas disponibles. 
Para una mejor comprensión del rol de los moluscos en la prehistoria uruguaya, y dada las diferencias culturales de cada región durante el bloque temporal abarcado por los registros arqueomalacológicos, se sintetiza a continuación la información disponible por región: comprendiendo, la región Este al litoral Atlántico; la región Centro-Sur a la costa del Río de la Plata; y la región Oeste al valle del río Uruguay.

Región Este

Los registros arqueomalacológicos en esta región representan un total de 22 especies utilizadas (Tabla 2). Las mismas comprenden bivalvos y gasterópodos de ambientes marinos $(n=15)$, dulceacuícolas $(n=3)$, terrestres $(n=2)$ y mixohalinos $(n=1)$, no pudiéndose determinar en un caso ya que su identificación se realiza a nivel de género. Los mismos fueron localizados mayoritariamente (en cuanto a cantidad de especies y número de restos) en sitios costeros (9 sitios; 16 especies). También fueron identificados en sitios del interland tanto en cerritos de indios ( 3 sitios; 8 especies) como en planicies asociadas a la Laguna de Castillos (1 sitio; 2 especies) (Tabla 2).

Para los sitios de la costa atlántica, a partir de asociaciones materiales, modificaciones térmicas (López Mazz et al. 2009a, Villarmarzo 2010) y patrones de fractura en gasterópodos (López Mazz 1995b) algunas especies, como Donax hanleyanus, Amiantis purpurata, Olivancillaria auricularia, Pachycymbiola brasiliana y Buccinanops cochlidium, fueron vinculadas al consumo. También fueron halladas especies formatizadas en contextos de actividades cotidianas (López Mazz y Gascue 2007, Mañosa 1995, Villarmarzo 2010) y funerarias (Seijo 1930). Estas modificaciones se vinculan, a la vida tecno-económica de los grupos, exclusivamente a partir de valvas de Amiantis purpurata que fueron seleccionadas como materia prima para la fabricación de artefactos utilitarios cortantes mediante técnicas de retoque, halladas en los sitios Cerro Buena Vista, La Coronilla y La Esmeralda (Figura 2A) (López Mazz 1995b, López Mazz y Gascue 2007, Mañosa 1995). Por otra parte, las especies marinas, como Olivancillaria auricularia, Olivancillaria urceus, Urosalpinx haneti, Conus lemniscatus ${ }^{1}$, Buccinanops cochlidium y almejas dulceacuícolas (Orden Unionida) fueron utilizadas para manufacturar elementos ornamentales de uso personal (cuentas y/o pendientes) a partir de procedimientos de perforación y abrasión (Bonino de Langguth 1961, Doello-Jurado 1940, Maeso 1977, Maruca Sosa 1957, Seijo 1930, Villarmarzo 2010). Estos materiales ornamentales han sido hallados en cinco de los diez sitios costeros atlánticos que presentan registros arqueomalacológicos, particularmente en Punta del Diablo, La Esmeralda (Figura 2B), Cabo Polonio (Rocha), José Ignacio (Figura 2C) y Punta del Este (Maldonado). En el caso de la localidad arqueológica de Punta del Este, los ornamentos se encuentran asociados a un enterratorio humano de un infante (Seijo 1930). Se evidenciaría así el uso simbólico de estas especies de moluscos para los grupos cazadores-recolectores de la costa atlántica, tanto como vehículo de diferenciación social (tecnologías de señalización costosa) como en el tratamiento de los muertos. 


\begin{tabular}{|c|c|c|c|c|c|c|c|}
\hline Sitio & ID Original & Reidentificación - Taxón & $\mathrm{n}$ relevadd & Hallazgo & Estado & Uso & Fuente \\
\hline \multirow{6}{*}{1 San Luis } & Unio charruanus & \begin{tabular}{|l|} 
Diplodon sp. \\
\end{tabular} & nd & estratigráfico & nd & ajuar funerario & \multirow{2}{*}{$\begin{array}{c}\text { Arechavaleta } \\
1892\end{array}$} \\
\hline & Trochus & Agathistoma patagonicum & nd & estratigráfico & nd & ajuar funerario & \\
\hline & Urosalpinx Rushii & Urosalpinx haneti & nd & --- & modificado & ornamental & \begin{tabular}{|c|} 
Doello-Jurado 1917, \\
1940 \\
\end{tabular} \\
\hline & -- & Ostrea puelchana & $\mathrm{NR}=1$ & --- & modificado perforado & ornamental & $\begin{array}{l}\text { Col. Maeso; } \\
\text { este trabajo }\end{array}$ \\
\hline & Olivancilaria brasiliensis & Olivancillaria urceus & nd & \multirow{2}{*}{ estratigráfico } & nd & nd & \multirow{2}{*}{ Maeso 1977} \\
\hline & Tegula patachónica & Agathistoma patagonicum & nd & & modificado perforado & ornamental & \\
\hline 2 CG14E01 & Diplodon sp. & Diplodon sp. & $\mathrm{NR}=2$ & estratigráfico & completas & ajuar funerario & Cabrera et al. 2000 \\
\hline \multirow{4}{*}{$3 \mathrm{CH} 2 \mathrm{D} 01$} & Glycimeris longior & Glycymeris longior & nd & \multirow{4}{*}{ estratigráfico } & nd & ajuar funerario & \multirow{4}{*}{$\begin{array}{c}\text { Bracco 1992; López } \\
\text { Mazz 1995a }\end{array}$} \\
\hline & Pomacea canaliculata & Pomacea canaliculata & nd & & nd & $\begin{array}{l}\text { consumo } \\
\text { (implícito) }\end{array}$ & \\
\hline & Diplodon paralelopípedon & Diplodon parallelopipedon & nd & & nd & $\begin{array}{l}\text { consumo } \\
\text { (implícito) }\end{array}$ & \\
\hline & Diplodon charruanus & Diplodon charruanus & nd & & nd & $\begin{array}{l}\text { consumo } \\
\text { (implícito) }\end{array}$ & \\
\hline \multirow{5}{*}{4 La Coronilla } & Amiantis purpurata & Amiantis purpurata & $\mathrm{NR}=138$ & estrati. y sup & comp. y frag. & consumo & López Mazz 1995b \\
\hline & Amiantis purpurata & Amiantis purpurata & $\mathrm{NR}=102$ & sup. & $\begin{array}{l}\text { modificado: } \\
\text { fracturado y retocado }\end{array}$ & $\begin{array}{c}\text { soporte } \\
\text { instrumento } \\
\text { tallado }\end{array}$ & Mañosa 1995 \\
\hline & Olivancilaria urseus & Olivancillaria auricularia & $\mathrm{NR}=41$ & \multirow{3}{*}{ estratigráfico } & comp. y frag. & consumo & \multirow{3}{*}{ López Mazz 1995b } \\
\hline & Adelodemo brasiliana & Pachycymbiola brasiliana & nd & & comp. y frag. & consumo & \\
\hline & Bucinanopus lamarkie & Buccinanops cochlidium & nd & & comp. y frag. & consumo & \\
\hline 5 Cerro Verde & Valvas & A realizar & nd & sup. & nd & nd & Gianotti et al. 2007 \\
\hline 6 La Moza & Stramonita haemastoma & Stramonita brasiliensis & $N R=13$ & estratigráfico & Fragmentadas & $\begin{array}{c}\text { antrópica } \\
\text { desconocida }\end{array}$ & Gascue et al. 2016a \\
\hline $\begin{array}{l}7 \text { Punta del } \\
\text { Diablo }\end{array}$ & Univalvas & $\begin{array}{c}\text { Urosalpinx haneti; } \\
\text { Buccinanops cochlidium }\end{array}$ & $\begin{array}{l}N R=15 \\
N R=1\end{array}$ & -- & modificado perforado & ornamental (collar) & Maruca Sosa 1957 \\
\hline \multirow{15}{*}{8 La Esmeralda } & Donax hanleyanus & Donax hanleyanus & $\begin{array}{l}\text { NMI }= \\
55.132 \\
\end{array}$ & \multirow{15}{*}{ estratigráfico } & comp. y frag. & consumo & \multirow{15}{*}{$\begin{array}{c}\text { Castiñeira et al. } \\
\text { 2007; Villarmarzo } \\
2010\end{array}$} \\
\hline & Amiantis purpurata & Amiantis purpurata & $N R=35$ & & $\begin{array}{c}\text { modificado fracturado } \\
\text { y retocado }\end{array}$ & $\begin{array}{c}\text { soporte } \\
\text { instrumento } \\
\text { tallado }\end{array}$ & \\
\hline & Olivancillaria auricularia & Olivancillaria auricularia & $\mathrm{NR}=28$ & & comp. y frag. & consumo & \\
\hline & Olivancillaria auricularia & Olivancillaria auricularia & $\mathrm{NR}=4$ & & modificado perforado & ornamental & \\
\hline & Glycymeris longior & Glycymeris longior & $\mathrm{NR}=25$ & & comp. y frag. & $\begin{array}{c}\text { antrópica } \\
\text { desconocida }\end{array}$ & \\
\hline & Bulimulus corderoi & $\begin{array}{l}\text { Bulimulus grupo } \\
\text { gorritiensis/corderoi }\end{array}$ & $\mathrm{NR}=25$ & & fragmentadas & intrusivo & \\
\hline & Pomacea canaliculata & Pomacea canaliculata & $\mathrm{NR}=13$ & & fragmentadas & posible consumo & \\
\hline & Austroborus lutescens & Austroborus lutescens & $\mathrm{NR}=4$ & & comp. y frag. & intrusivo & \\
\hline & Urosalpinx sp. & Urosalpinx haneti & $\mathrm{NR}=1$ & & nd & $\begin{array}{l}\text { antrópica } \\
\text { desconocida }\end{array}$ & \\
\hline & Erodona mactroides & Erodona mactroides & $N R=1$ & & nd & $\begin{array}{l}\text { antrópica } \\
\text { desconocida }\end{array}$ & \\
\hline & Mactra sp. & Mactra sp. & $\mathrm{NR}=102$ & & fragmentadas & $\begin{array}{c}\text { antrópica } \\
\text { desconocida }\end{array}$ & \\
\hline & Adelomelon brasiliana & Pachycymbiola brasiliana & nd & & nd & nd & \\
\hline & Pitar rostratus & Pitar patagonicus & nd & & nd & nd & \\
\hline & Tivela isablelleana & Eutivela isabelleana & nd & & nd & nd & \\
\hline & & nd & $N R=1$ & & $\begin{array}{c}\text { modificado pulido y } \\
\text { perforado }\end{array}$ & $\begin{array}{c}\text { ornamental } \\
\text { (cuenta) }\end{array}$ & \\
\hline $\begin{array}{l}9 \text { Cerro Buena } \\
\text { Vista }\end{array}$ & Amiantis purpurata & Amiantis purpurata & $N R=1$ & sup. & $\begin{array}{l}\text { modificado } \\
\text { retocado }\end{array}$ & $\begin{array}{l}\text { soporte } \\
\text { instrumento } \\
\text { tallado }\end{array}$ & $\begin{array}{l}\text { López Mazz y } \\
\text { Gascue } 2007\end{array}$ \\
\hline \multirow{6}{*}{10 Cabo Polonio } & --- & Austroborus lutescens & nd & sup. & comp. y frag. & consumo & Este trabajo \\
\hline & Olivancilaria brasiliana & Olivancillaria urceus & nd & sup. & modificado perforado & $\begin{array}{l}\text { ornamental } \\
\text { (pendientes) }\end{array}$ & Bonino 1961 \\
\hline & Pitaria Rostrata & Pitar patagonicus & nd & sup. & nd & consumo & \multirow{4}{*}{ Baeza et al. 1980} \\
\hline & Olivancillaria Vesica & Olivancillaria auricularia & nd & sup. & nd & consumo & \\
\hline & Thais Haemastoma & Stramonita brasiliensis & nd & sup. & nd & consumo & \\
\hline & Pachycymbiola Brasiliana & Pachycymbiola brasiliana & nd & sup. & nd & consumo & \\
\hline \multirow{2}{*}{$\begin{array}{l}11 \text { Guardia del } \\
\text { Monte }\end{array}$} & Valva de molusco & Crassostrea praia & $\mathrm{NR}=1$ & \multirow[t]{2}{*}{ estratigráfico } & fósil & \multirow{2}{*}{$\begin{array}{l}\text { Antrópico } \\
\text { desconocido }\end{array}$} & $\begin{array}{c}\text { Capdepont et al. } \\
2016\end{array}$ \\
\hline & --- & Pachycymbiola brasiliana & $\mathrm{NR}=1$ & & fragmentado & & Este trabajo \\
\hline 12 José Ignacio & Urosalpinx Rushi & $\begin{array}{l}\text { Urosalpinx haneti; } \\
\text { Conus lemniscatus }\end{array}$ & $\begin{array}{l}\mathrm{NR}=25 \\
\mathrm{NR}=1\end{array}$ & estratigráfico & $\begin{array}{l}\text { modificados } \\
\text { perforados }\end{array}$ & ornamental (collar) & $\begin{array}{l}\text { Maeso 1977; } \\
\text { Col. Maeso; } \\
\text { este trabajo }\end{array}$ \\
\hline 13 Punta del Este & $\begin{array}{c}\text { Almeja de río } \\
\text { (Unio-Anodonta) }\end{array}$ & Unionida & $\mathrm{NR}=11$ & estratigráfico & $\begin{array}{l}\text { modificado pulido y } \\
\text { perforado }\end{array}$ & $\begin{array}{l}\text { ajuar funerario } \\
\text { (cuentas) }\end{array}$ & Seijo 1930 \\
\hline
\end{tabular}

Tabla 2. Registros arqueomalacológicos en sitios de la región Este²

En los sitios costeros del Atlántico, existe un número considerable de otras especies marinas (Glycymeris longior, Pitar patagonicus, Eutivela isabelleana y Stramonita brasiliensis), estuarinas (Erodona mactroides), dulceacuícolas (Pomacea canaliculata) y terrestres (Bulimulus grupo gorritiensis/corderoi y Austroborus lutescens), recuperadas principalmente en el conchero de La Esmeralda (Castiñeira et al. 2007, Villarmarzo 2010) y en menor medida en 
las penínsulas rocosas de Cabo Polonio (Baeza et al. 1980) y La Moza (Gascue et al. 2016a). Estas últimas especies, por hallarse en escasas proporciones, en niveles superiores caracterizados por mezcla de materiales prehispánicos e históricos, o porque simplemente los investigadores no le adscriben una funcionalidad específica, fueron catalogados como de origen antrópico desconocido.

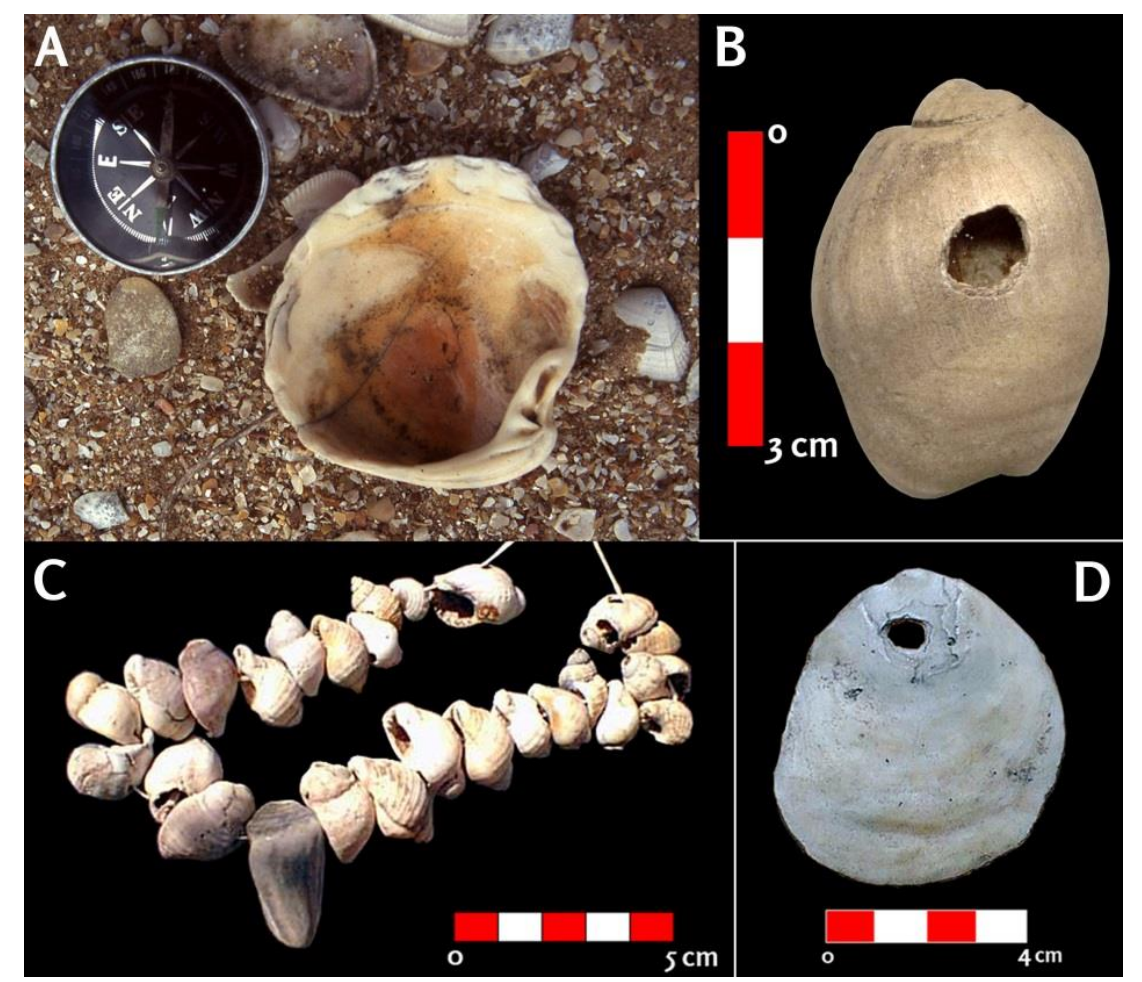

Figura 2: Artefactos sobre moluscos de la región Este; A) Instrumento retocado en valva de $A$. purpurata (hallazgo superficial sitio La Esmeralda); B) Caparazón perforado de O. auricularia, La

Esmeralda, Exc I (tomado de Villarmarzo 2010); C) Cuentas perforadas en U. haneti y una conchilla de C. lemniscatus, José Ignacio (colección Maeso); D) Cuenta con perforación subcentral en O. puelchana procedente de un cerrito de San Luis (colección Maeso).

Los registros más conspicuos de esta región

se asocian a sitios localizados en arcos de playa, particularmente al sitio La Esmeralda, caracterizado como tres concheros (Castiñeira et al. 2007) producidos por la adquisición, consumo y descarte in situ de varias especies. Entre estas destacan Donax hanleyanus (ver NMI en Tabla 2) y Olivancillaria auricularia, especies que ocupan el mismo hábitat: zona de barrido o "swash" (Scarabino et al. 2006a y b). Las conchillas de Pachycymbiola brasiliana presentan fracturas en la última vuelta, lo que ha sido propuesto como evidencia de consumo alimenticio (López Mazz 1995b). Sin embargo, esto debería confirmarse con estudios experimentales, ya que es incierto si es necesario quebrar la última vuelta para la extracción del pie luego de ser cocido. Esta especie, junto a Amiantis purpurata, puede estar disponible luego de mortandades por eventos extremos de disminución de salinidad y/o temporales, siendo especies que viven en la zona entre ca. 5-20 m de profundidad (Carranza et al. 2008, Scarabino et al. 2006a y b, Scarabino et al. 2016b). Para el resto de especies marinas y estuarinas detectadas en este sitio, por estar subrepresentadas, hallarse desgastadas en algunos casos o por no 
conocerse el estado de las valvas, no es posible adscribir su utilización como alimento. Las especies continentales como la dulceacuícola Pomacea canaliculata y las terrestres Austroborus lutescens y Bulimulus sp. grupo gorritiensis/corderoi se encuentran actualmente disponibles con vida en cañadas y bañados de la zona costera en el primer caso y en ambientes dunares costeros en el segundo y tercero (Scarabino 2004a), por lo cual la captura del animal completo y su consumo no puede ser descartada.

Precisamente respecto a A. lutescens, es de destacar el hallazgo de un depósito de conchas (cf. Dupont 2006) de esta especie localizado en un espacio interdunar de la playa sur de Cabo Polonio, distante $6 \mathrm{~km}$ de la península. El mismo se caracteriza por una concentración superficial en relieve de planta circular de $5 \mathrm{~m}$ de diámetro, expuesta por la deflación eólica de las arenas, asociada a numerosos artefactos líticos en cuarzo y granito de Cabo Polonio y otros restos óseos faunísticos de vertebrados y moluscos marinos (Amiantis purpurata y Olivancillaria auricularia) (Figura 3). Las características de este nuevo hallazgo confirman que los gasterópodos terrestres formaron parte del espectro dietario de las poblaciones prehispánicas costeras, y a su vez posibilita re-caracterizar funcionalmente a los moluscos terrestres recuperados en el sitio La Esmeralda.

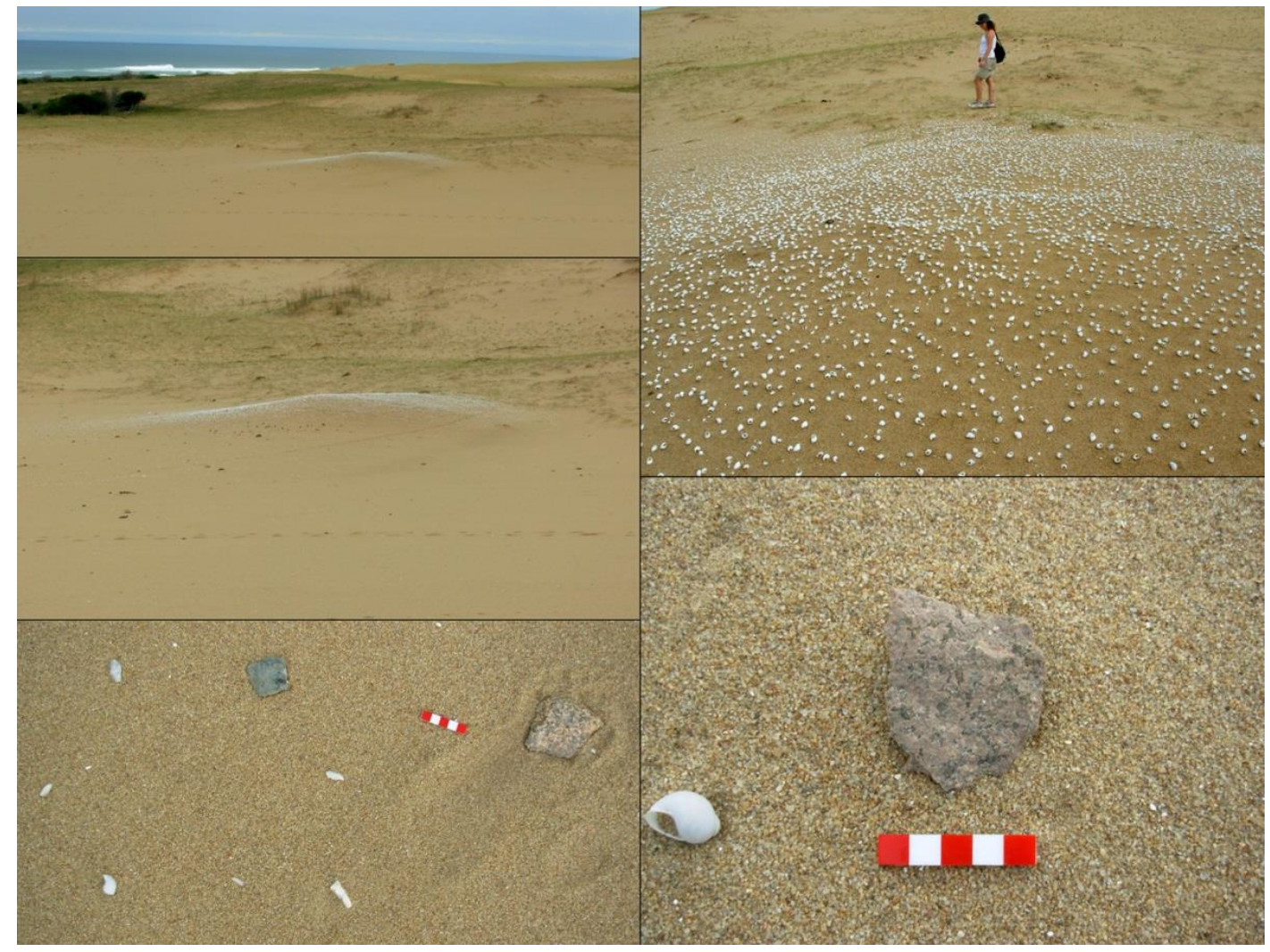

Figura 3: Depósito antrópico de Austroborus lutescens localizado en playa sur de Cabo Polonio; contexto de hallazgo y detalle de materiales líticos y óseos asociados.

A partir de las investigaciones llevadas adelante en el sitio La Esmeralda, se plantearon hipótesis que implican la implementación de nuevas estrategias económicas vinculadas a un proceso de intensificación en la explotación de moluscos hacia ca. 3000 
AP (López Mazz y Villarmarzo 2009). Si bien la explotación y consumo alimenticio de moluscos está bien documentada para estos momentos, la información anterior al 3000 AP es escasa y fragmentaria (únicamente representada por el sitio Cabo Polonio [península], López Mazz 1994-95, López Mazz et al. 2009b) como para proponer que se trata de nuevas estrategias y de una intensificación económica, en la medida que estos conceptos involucran una profundidad temporal (Borseup 1965, en Zangrado 2009) aún poco conocida. Respecto al peso en la economía que suponen los moluscos para estas poblaciones costeras, en el caso de La Esmeralda (sitio donde la explotación de moluscos alcanza los niveles más altos conocidos hasta el momento), los cálculos de biomasa (sobre la muestra arqueofaunística de la excavación I) combinando el NMI de individuos con datos experimentales, arroja valores de $50 \mathrm{~kg}$ de pulpa de Donax (NMI=55.132) contra 224-447 kg de vertebrados (Moreno 2014). Para estos últimos solo se incluyen los restos de los mamíferos Arctocephalus australis (NMI=2), Ozotocerus bezoarticus (NMI=4) y Dasypus sp. (NMI=3), no considerando otros grupos con un número significativo de restos en el registro como tortugas, peces, roedores y aves (Moreno 2005). De esto se desprende que para el sitio La Esmeralda, los moluscos tuvieron un papel secundario en las dietas. Para los restantes sitios de la costa atlántica, basados en el reducido número de restos, modificaciones y contexto de hallazgo (Tabla 2) su consumo alimenticio habría sido marginal o nulo.

Dentro de los sitios costeros del litoral Atlántico en que se registraron moluscos, tres cuentan con fechados radiocarbónicos (La Esmeralda, La Coronilla y La Moza). Los registros más tempranos, tanto a nivel nacional, que evidencian consumo y producción de elementos ornamentales se localizan en la mayor de las tres estructuras del sitio La Esmeralda (estructura A). Dicha estructura con cronologías entre el $3300 \pm 40$ años AP y $2360 \pm 70$ años AP, con varios fechados intermedios (Castiñeira et al. 2007, Villarmarzo 2010) (Tabla 1) permite inferir que fue generada en un período acotado de tiempo, con al menos dos momentos de ocupación diferenciados en la horizontal (ver Castiñeira et al. 2007). La cronología del sitio se completa con un fechado para la estructura C, de $3190 \pm 80$ años AP, contemporánea al sector Este de la A. Asimismo, dos fechados de la estructura B estarían indicando un tercer momento de ocupación del yacimiento en $1080 \pm 60$ y $1000 \pm 70$ años AP (Castiñeira et al. 2007). Para dos de las tres estructuras (A y B) se cuenta con fechados sobre Donax hanleyanus y sobre carbón cultural, lo que indica, según Bracco et al. (1999) que el efecto reservorio es estadísticamente indiferenciable. Esto refuerza el carácter antrópico de las acumulaciones y brinda un buen marco de referencia a los fechados sobre moluscos realizados para otros sitios del litoral atlántico (i.e. La Coronilla). Complementariamente,

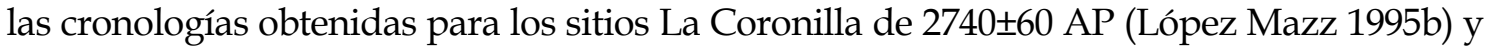
el sitio La Moza de 2490 \pm 30 años AP (Gascue et al. 2016a) 3 sitúan en conjunto (y provisionalmente) el aprovechamiento de diversos moluscos obtenidos de distintos ambientes en el Holoceno tardío. El contexto temporal en el que se ubican los primeros registros significativos de explotación de moluscos, coincide con cambios climáticos asociados a un leve descenso del nivel del mar hacia el ca. 3000 años AP (Ayup 1991) y recrudecimiento de las condiciones ambientales (Inda et al. 2011). Las características del recurso en cuanto a accesibilidad, predictibilidad, reducción de los niveles de 
dependencia etaria involucrados en su adquisición, su menor retorno energético (Perlman 1980, Yesner 1980) y lo fragmentario del registro a nivel regional nos hace proponer a los moluscos como un recurso "consuelo". Esta última característica implica que posiblemente se habría recurrido a su consumo en momentos de estrés alimenticio o, como recurso complementario bajo condiciones ambientales más benévolas.

Por otra parte, en los registros del interland, los moluscos se encuentran en cerritos ubicados en el departamento de Rocha, principalmente formando parte de ajuares funerarios. En el sitio CG14E01 (Isla Larga) se caracterizan por la presencia de valvas de Diplodon sp. sin modificaciones, que forman parte de un ajuar compuesto además por dos núcleos bipolares de cuarzo, hemimandíbulas de zorros (Dusicyon gymnocercus y Cerdocyon thous) y nutria (Myocastor coypus), placas de peludo (Euphractus sexcinctus) y restos combustión. El conjunto se encontró inmediatamente encima de un enterratorio de un infante de 10 meses y contiguo a un enterratorio primario correspondiente a un individuo masculino de 20 años de edad, lo que imposibilitó atribuir la ofrenda a uno u otro (Cabrera et al. 2000). Estos hallazgos se sitúan en un período comprendido entre el 1610 y 220 años AP, al cual corresponde el rango cronológico de los enterratorios (Figueiro et al. 2017) (Tabla 1).

Por su parte, en el sitio CH2D01 compuesto por dos cerritos, localizados en el bañado de San Miguel, a 14,7 km de la costa, se hallaron enterratorios primarios y secundarios con ajuares. Estos contenían moluscos bivalvos marinos (Glycymeris longior) que, junto con un diente de lobo marino llevó a proponer relaciones de tipo no especificada (identidad cultural o intercambios) entre los constructores de cerritos y los grupos que ocuparon el litoral costero (Bracco 1992). Tanto en CH2D01 como en CG14E01 las valvas se dispusieron con las caras internas hacia arriba (Bracco 1992: 41; Figura 10 en Cabrera et al. 2000:194) lo que, pese a lo limitado de la evidencia caracterizada por dos hallazgos, podría indicar un patrón en cuanto a la utilización de estos elementos en contextos funerarios. Para el sitio CH2D01 también se identificaron dos especies de bivalvos del género Diplodon ( $D$. parallelopipedon y D. charruanus), otros bivalvos Unionida sin determinar, y gasterópodos (Pomacea canaliculata) (López Mazz 1995a) que, por estar asociados a restos de alimentación, se relacionan implícitamente a la dieta de los constructores de cerritos (Bracco 1992). Sin embargo, no se menciona como los restos se distribuyen en las excavaciones (dispersos, en lentes, etc.) y tampoco han sido cuantificados, lo que dificulta ponderar el rol que ocuparon en las dietas de estas poblaciones, así como adjudicarles cronologías específicas más allá del rango de ambas elevaciones (2430-340 años AP; ver Tabla 1).

La evidencia en los cerritos se completa con restos de tres especies marinas Urosalpinx haneti, Agathistoma patagonicum y Ostrea puelchana- recuperados en la zona del río San Luis (Rocha) (Arechavaleta 1892; Doello-Jurado 1940; Maeso 1977). Estas conchillas, que actualmente se hallan en la costa rochense en forma abundante, presentan evidencias de modificación antrópica entre las que se destacan las 
perforaciones y a las que se les atribuyen funciones ornamentales personales (DoelloJurado, 1940, Maeso, 1977). Particularmente, en la colección Maeso se conserva una valva de Ostrea puelchana, con perforación subcentral (Figura 2d). Hasta el momento, el conjunto de evidencias de sitios tierra adentro indica, que la malacofauna presente en los cerritos se relaciona principalmente con la esfera simbólica de estos grupos cazadores-recolectores, desempeñando un rol de escaso peso en las dietas humanas respecto a otros tipos de recursos alimenticios (vertebrados).

Finalmente se presenta el caso de un enterratorio secundario femenino recuperado en la planicie de la Laguna de Castillos en el sitio Guardia del Monte (GMII), asociado a restos de fauna de vertebrados y dos restos malacológicos (Capdepont et al. 2016). Estos últimos se caracterizan por una valva de ostra fósil del género Crassostrea (Crassostrea praia) y un caparazón de Pachycymbiola brasiliana con fractura en la última vuelta. El enterratorio se

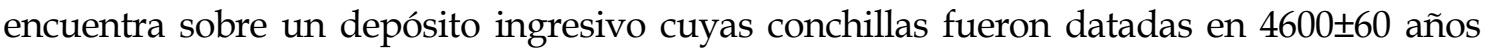
AP y en una capa que contiene otros restos faunísticos. Considerando el contexto de hallazgo, la asociación directa del enterramiento con restos de moluscos es difícil de establecer. En este sentido, la presencia de moluscos puede estar formando parte de un ajuar funerario. Asimismo, ambas pudieron formar parte del contexto económico o del depósito subyacente; esto solo podrá resolverse con un estudio exhaustivo de dicho depósito.

\section{Región Centro-Sur}

Los sitios se localizan en los departamentos de San José (Arazatí, Ao San Gregorio y Colonización) y Canelones (Gambé y Piedras de Afilar) en su mayoría estrechamente vinculados a líneas de paleocostas generadas por las oscilaciones holocénicas del nivel marino (Beovide 2010, Beovide y Malán 2003). En estos cinco sitios arqueológicos, se ha registrado la presencia de 11 especies de moluscos (bivalvos y gasterópodos) de ambientes mixohalinos $(n=6)$ y marinos $(n=4)$, no pudiéndose determinar en un caso ya que su identificación se realiza a nivel de género (Tabla 3). Para algunas especies descritas en la literatura, el origen antrópico será discutido en este trabajo.

Al igual que en la Región Este, se ha propuesto el uso económico para algunos recursos malacológicos, principalmente Erodona mactroides (Beovide 2013, Beovide y Martínez 2014, Beovide et al. 2015a). No obstante, la mayor cantidad de evidencias indican que el uso de una diversidad mayor de especies se orientó a los aspectos simbólicos de la cultura, utilizados para la fabricación de ornamentos personales (ver entre otros Beovide 2009, 2010, Beovide et al. 2015b, Bonino de Langguth 1961, Maruca Sosa 1957).

Las especies mayoritariamente utilizadas para la fabricación de ornamentos no se encuentran actualmente disponibles a nivel regional, ni lo habrían estado en los contextos cronológicos referidos, ya que se trata de especies marinas como los caracoles Urosalpinx haneti, Costoanachis sertulariarum, Olivancillaria urceus y la lapa Diodora patagonica, recuperadas en los yacimientos de Piedras de Afilar, Arroyo San 
Gregorio y Arazatí (Tabla 3). Mención especial merecen los hallazgos de centenas de cuentas de $U$. haneti, que conforman un ajuar funerario asociado a un enterramiento doble de individuos infantiles cubiertos de ocre en el sitio Arazatí (Beovide et al. 2015b, Bonino de Langguth 1961, Penino 1957, en Maruca Sosa 1957) (Tabla 3). Dichas cuentas, en base a su cantidad y algunas marcas, fueron interpretadas como parte de un soporte (de cuero o textil) y tienen la particularidad de presentar una cronología ca. 400 años más antigua que el enterramiento (Beovide et al. 2015b; Tabla 1). Esta situación, junto con el hábitat y ocurrencia de la especie (Scarabino et al. 2006a) indica que se habrían adquirido sin vida (solo los caparazones) en los cordones de playas oceánicas de la región Este (distantes al menos $240 \mathrm{~km}$ del sitio). Esto último puede extenderse a las tres restantes especies ornamentales registradas en la región.

\begin{tabular}{|c|c|c|c|c|c|c|c|}
\hline Sitio & ID Original & $\begin{array}{c}\text { Reidentificación - } \\
\text { Taxón }\end{array}$ & $\mathrm{n}$ relevado & Hallazgo & Estado & Uso & Fuente \\
\hline $\begin{array}{c}14 \\
\text { Piedras } \\
\text { de Afilar }\end{array}$ & valvas & $\begin{array}{c}\text { Diodora } \\
\text { patagonica }\end{array}$ & $N R=8$ & --- & $\begin{array}{l}\text { completas con } \\
\text { perforación } \\
\text { natural }\end{array}$ & $\begin{array}{l}\text { ornamental } \\
\text { (collar) }\end{array}$ & $\begin{array}{c}\text { Maruca Sosa } \\
1957\end{array}$ \\
\hline \multirow{6}{*}{$\begin{array}{c}15 \\
\text { Coloniza- } \\
\text { ción }\end{array}$} & $\begin{array}{c}\text { Erodona } \\
\text { mactroides }\end{array}$ & $\begin{array}{c}\text { Erodona } \\
\text { mactroides }\end{array}$ & nd & \multirow{6}{*}{ estratigráfico } & comp. y frag. & consumo & \multirow{6}{*}{$\begin{array}{c}\text { Beovide } \\
\text { 2013; } \\
\text { Beovide y } \\
\text { Martínez } \\
\text { 2014; } \\
\text { Beovide } \text { et al. } \\
\text { 2015a }\end{array}$} \\
\hline & Heleobia sp. & Heleobia sp. & nd & & nd & $\begin{array}{c}\text { recolección no } \\
\text { selectiva o } \\
\text { material } \\
\text { constructivo o } \\
\text { natural } \\
\end{array}$ & \\
\hline & $\begin{array}{l}\text { Tagelus } \\
\text { plebeius }\end{array}$ & Tagelus plebeius & nd & & nd & nd & \\
\hline & $\begin{array}{c}\text { Anomalocardia } \\
\text { brasiliana }\end{array}$ & $\begin{array}{c}\text { Anomalocardia } \\
\text { brasiliana }\end{array}$ & nd & & nd & nd & \\
\hline & Mactra sp. & Mactra sp. & nd & & nd & nd & \\
\hline & Ostrea spreta & Ostrea spreta & nd & & nd & nd & \\
\hline \multirow{5}{*}{$\begin{array}{c}16 \\
\text { Gambé }\end{array}$} & $\begin{array}{c}\text { Erodona } \\
\text { mactroides }\end{array}$ & $\begin{array}{c}\text { Erodona } \\
\text { mactroides }\end{array}$ & $\begin{array}{l}\mathrm{NMI}= \\
763\end{array}$ & \multirow{5}{*}{ estratigráfico } & comp. y frag. & consumo & \multirow{5}{*}{$\begin{array}{c}\text { Beovide 2013; } \\
\text { Beovide y } \\
\text { Lorenzo 2014; } \\
\text { Beovide y } \\
\text { Martínez 2014; } \\
\text { Beovide et al. } \\
\text { 2015a }\end{array}$} \\
\hline & $\begin{array}{c}\text { Erodona } \\
\text { mactroides }\end{array}$ & $\begin{array}{l}\text { Erodona } \\
\text { mactroides }\end{array}$ & nd & & $\begin{array}{l}\text { modificado } \\
\text { fracturas y } \\
\text { perforados }\end{array}$ & $\begin{array}{l}\text { ornamental } \\
\text { (cuentas) y } \\
\text { soporte } \\
\text { instrumentos }\end{array}$ & \\
\hline & Heleobia sp. & Heleobia sp. & $\begin{array}{l}\mathrm{NMI}= \\
19.769\end{array}$ & & comp. y frag. & $\begin{array}{c}\text { recolección no } \\
\text { selectiva o } \\
\text { material } \\
\text { constructivo o } \\
\text { natural } \\
\end{array}$ & \\
\hline & $\begin{array}{l}\text { Tagelus } \\
\text { plebeius }\end{array}$ & Tagelus plebeius & nd & & nd & nd & \\
\hline & $\begin{array}{c}\text { Ostrea } \\
\text { equestris }\end{array}$ & Ostrea equestris & nd & & nd & nd & \\
\hline $\begin{array}{c}17 \\
A^{\circ} \text { San } \\
\text { Gregorio }\end{array}$ & $\begin{array}{c}\text { Olivancillaria } \\
\text { vesica } \\
\text { auricularia }\end{array}$ & $\begin{array}{c}\text { Olivancillaria } \\
\text { urceus }\end{array}$ & $N R=30$ & --- & $\begin{array}{l}\text { modificado } \\
\text { perforado }\end{array}$ & ornamental & $\begin{array}{c}\text { Beovide y } \\
\text { Lorenzo } 2014\end{array}$ \\
\hline \multirow{3}{*}{$\begin{array}{c}18 \\
\text { Arazatí }\end{array}$} & $\begin{array}{l}\text { Urosalpinx } \\
\text { Rushii }\end{array}$ & $\begin{array}{l}\text { Urosalpinx } \\
\text { haneti }\end{array}$ & $N R>300$ & estratigráfico & $\begin{array}{c}\text { modificado } \\
\text { fracturas, pulido } \\
\text { y/o perforación }\end{array}$ & $\begin{array}{l}\text { ajuar funerario } \\
\text { (cuentas) }\end{array}$ & $\begin{array}{c}\text { Maruca Sosa } \\
\text { 1957; Bonino } \\
\text { 1961; } \\
\text { Beovide et al. } \\
\text { 2015b }\end{array}$ \\
\hline & Anachis & $\begin{array}{l}\text { Costoanachis } \\
\text { sertulariarum }\end{array}$ & $\begin{array}{l}\text { "nume- } \\
\text { rosos" }\end{array}$ & sup. & $\begin{array}{l}\text { modificado } \\
\text { perforado }\end{array}$ & $\begin{array}{l}\text { ornamental } \\
\text { (collar) }\end{array}$ & Bonino 1961 \\
\hline & $\begin{array}{c}\text { pelecípodos } \\
\text { [bivalvos] } \\
\text { de agua dulce }\end{array}$ & A realizar & varios & --- & $\begin{array}{l}\text { modificado } \\
\text { perforados y } \\
\text { pulidos }\end{array}$ & $\begin{array}{c}\text { ornamental } \\
\text { (cuentas) }\end{array}$ & Bonino 1961 \\
\hline
\end{tabular}

Tabla 3: Registros arqueomalacológicos en sitios de la región Centro-Sur (costa estuarina Río de la Plata). 
También se ha reportado la presencia, en el sitio Gambé, de un número no determinado de valvas de Erodona mactroides (de origen local) que se encuentran perforadas y han sido catalogadas como cuentas (Beovide 2009, 2013). Con excepción de los ejemplares de Diodora patagonica, que naturalmente están perforadas en la propia morfología de la conchilla, para las restantes especies ornamentales se describen procesos de manufactura por percusión, abrasión (Beovide et al. 2015b) y/o perforación (Beovide y Lorenzo 2014, Beovide et al. 2015b, Bonino de Langguth 1961). En el caso de D. patagonica, es el contexto de hallazgo (agrupadas en un yacimiento arqueológico) lo que conduce al autor a clasificarlas como cuentas de collar (Maruca Sosa 1957: 199). Para el sitio Gambé, además de la fabricación de cuentas sobre valvas de E. mactroides, se han reconocido sobre la misma especie fracturas distinguibles de las producidas naturalmente, que han sido asociadas a la producción de instrumentos sin más determinación (Beovide 2013).

Respecto al aprovechamiento económico de los moluscos en la región estuarina, se ha reportado la existencia de diversos concheros (Beovide 2009, Beovide y Campos 2015, Beovide et al. 2015a, 2017, Beovide y Martínez 2014) que llevaron a proponer un proceso de intensificación en la explotación de moluscos hacia el 2700 años AP (Beovide 2009, 2015). Con mayor profundidad se han estudiado los correspondientes a los sitios Gambé y Colonización. Para otros, como Cañada Las Conchas, Dianova, Punta Espinillo y Km 26 e, incluso los niveles inferiores del sitio Arazatí (Beovide y Campos 2015, Beovide et al. 2015a, 2017), solo se menciona su antigüedad y asociaciones de moluscos, pero no se describen materiales culturales claramente asociados a los niveles malacológicos. Es por esto que no se consideraron en este trabajo algunos de estos sitios catalogados como concheros ya que no presentan más datos empíricos que la propia atribución (ver Tabla 3).

El sitio Gambé se sitúa en el valle del Río Santa Lucía en cota 4,5 msnm, emplazado sobre un cordón de la Formación Villa Soriano. Esta formación, si bien presenta dos facies (ubicadas en el Pleistoceno tardío y Holoceno medio), en la cuenca del Santa Lucía ha sido fechada en 5.870 \pm 90 años AP (Martínez y Ubilla 2009) lo que, en este caso la vincula a la ingresión marina del Holoceno medio. Presenta litologías variables según su localización ( $\mathrm{y}$ facie) entre pelitas y conglomerados (Bossi y Ferrando 2001) y contienen bancos de conchillas, marinas y estuarinas de potencia variable no consolidada (Goso y Bossi 1966). Sobre estos depósitos se desarrolla el sitio, presentando un sustrato arenoso donde se recuperaron materiales líticos, cerámicos, óseos y 50 concentraciones de moluscos en las que se identificaron tres especies; Erodona mactroides, Heleobia sp. y Ostrea equestris. Se estudiaron en profundidad dos de las concentraciones recuperadas en la excavación III, las cuales se presentan como pequeños lentes de $15 \times 13$ y $10 \times 8 \mathrm{~cm}$ de superficie (Figura $4 \mathrm{~A}$ ) fechadas sobre Erodona mactroides en $2365 \pm 32$ y $2409 \pm 32$ años AP respectivamente (Beovide 2013; Tablas 1 y 3). Ambas concentraciones se componen mayoritariamente del gasterópodo Heleobia sp. seguidas por el bivalvo Erodona mactroides en una relación de 26 a 1 individuos (Tabla 3). Dentro de este contexto, y a pesar que ambas especies presentan termoalteraciones, 
únicamente Erodona mactroides es asociada a actividades de consumo (Beovide 2013), interpretación sustentada en su considerable mayor retorno energético respecto a Heleobia sp. de escasa dimensión.

Otro de los sitios caracterizado como conchero -Colonización- en términos de Beovide (2013: 114) se caracteriza como un "montículo con una potencia aproximada de $2 \mathrm{~m}$. de valvas de moluscos". Para el mismo, se menciona la asociación de seis especies estuarinas/marinas eurihalinas (Erodona mactroides, Heleobia sp., Tagelus plebeius, Anomalocardia brasiliana, Mactra sp. y Ostrea spreta) (Tabla 3). A partir de esto se sugiere el marisqueo selectivo de las especies disponibles en el Río de la Plata, y de una recolección particularmente oportunística al explotar especies potencialmente disponibles (en aquel momento) en los alrededores de los sitios, como Erodona mactroides (Beovide et al. 2015a).

$\mathrm{Al}$ igual que Gambé, Colonización está compuesto mayoritariamente por sedimentos arenosos entre los 10 y $60 \mathrm{~cm}$ de profundidad (Beovide y Malán 2006) que apoyan en Fm. Villa Soriano (ver Figura 2 en Beovide y Malán 2006: 291). La ocupación humana está representada por artefactos líticos (tallados y pulidos) escasos restos cerámicos y restos de vertebrados, que se localizan hasta los $70 \mathrm{~cm}$ de profundidad (Beovide y Malán 2006). Si bien, ninguno de los artículos a los que se tuvo acceso presenta en detalle la estratigrafía del sitio en forma gráfica, "se observa que la matriz sedimentaria en los niveles con presencia de material arqueológico, no presentan diferencias en cuanto a las variables de textura color y granulometría" (Beovide y Malán 2006: 286). Esta información, en cuanto al alcance vertical de los materiales y características del sustrato en que se encuentran, combinada con la foto del perfil de excavación (sin escala) publicada en Beovide et al. (2015a) indica que los materiales provendrían del estrato superior (pardo oscuro). La capa inferior (color gris claro, dado seguramente por la alta proporción de conchillas) sería estéril desde el punto de vista arqueológico (Figura 4B) o los materiales se localizarían en la porción superior de esta última capa, pero nunca alcanzando los dos metros de potencia reportados para la estructura.

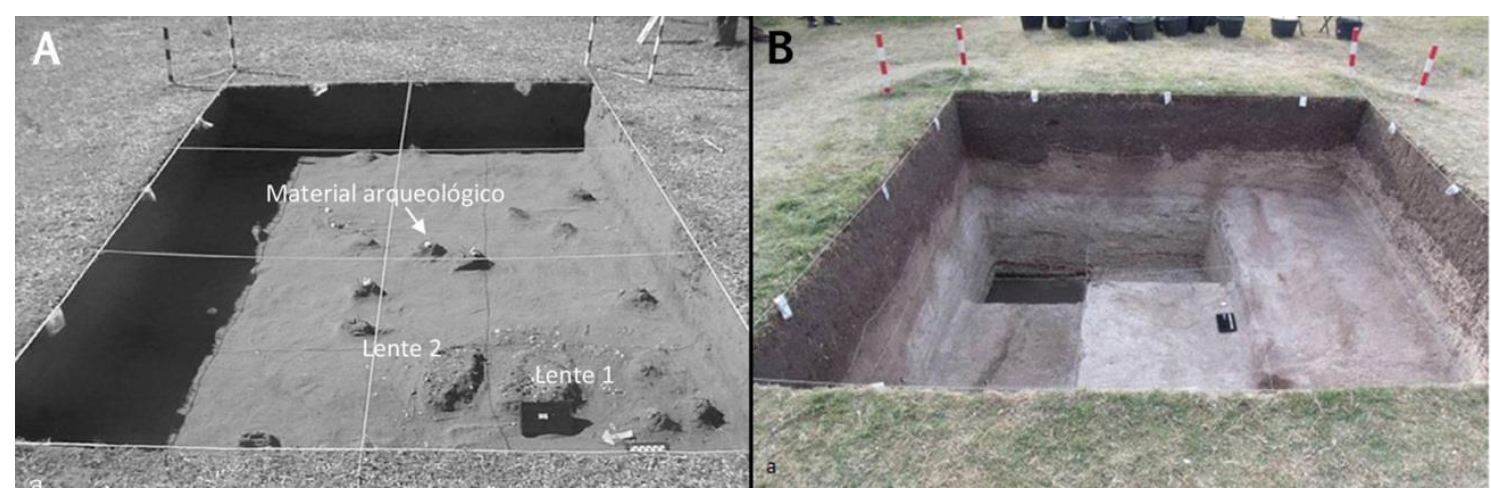

Figura 4: A) Planta de excavación del sitio Gambé donde se aprecia las reducidas dimensiones de los lentes con moluscos (tomado de Beovide 2013); B) Detalle del perfil de excavación del sitio Colonización donde se aprecia la existencia de dos capas bien diferenciadas a nivel colorimétrico (tomado de Beovide et al. 2015a). 
El porcentaje de conchas presente en un depósito necesario para la consideración o no como un conchero ha sido objeto de debate, aceptándose como valor medio un 30$50 \%$ de la composición total (Meighan 1980, Bowdler 2006). En este sentido, basados principalmente en la escasa cantidad y en las reducidas dimensiones de los lentes con moluscos hallados y que se encuentran termoalterados, consideramos cuestionable la adscripción del sitio Gambé como conchero, correspondiendo su situación más bien a un sitio doméstico, que entre otras muchas actividades incluyó en forma muy efímera el consumo de E. mactoides. Por otra parte, la presencia de Heleobia sp. en el sitio no ha sido suficientemente explicada. Esta se ha vinculado a la recolección no intencional durante la captura de Erodona, o bien como material constructivo, sin descartar la hipótesis natural (Beovide et al. 2015a). No obstante, consideramos que estas hipótesis no son concordantes con las proporciones de número de restos Heleobia vs Erodona halladas, ni con las escasas dimensiones de los lentes (que no se configuran como elementos pasibles de elevar apreciablemente al sitio), ni con la presencia natural de esta especie en un contexto doméstico de sustrato arenoso. En este sentido, y pese al escaso tamaño (menor a $1 \mathrm{~cm}$ en etapa adulta) y retorno energético, en función del contexto de hallazgo y por presentar termoalteraciones no puede descartarse su consumo o incluso otras funciones como materia prima para la producción cerámica.

En el mismo sentido, para el sitio Colonización, y extensiblemente para los restantes concheros reportados (Cañada Las Conchas, Dianova, Punta Espinillo y Km 26) consideramos que el carácter antrópico de las estructuras no ha sido hasta la fecha adecuadamente probado. Por el contrario, las escasas evidencias presentadas en los extensos artículos publicados sobre estos yacimientos (e.g. Beovide 2013, Beovide y Campos 2015, Beovide et al. 2015a, 2017) sugiere que se trataría de depósitos naturales, que en el caso de Colonización (único al que claramente se le asocia evidencia artefactual prehispánica) podría corresponder a una ocupación efectuada sobre una geoforma arenosa sobreyacente a la Fm. Villa Soriano, tal como fue en su momento caracterizado por Beovide (2007). De hecho, este patrón de ocupación del espacio está ampliamente documentado a nivel regional desde la Laguna de Castillos (e.g. Capdepont at al. 2016) hasta la provincia de Buenos Aires (e.g. Bonomo 2004) con locaciones intermedias como el sitio Conchillal de la Loma (Farías, 2005, Maeso 1977). Estas observaciones relativizan la utilización de la mayoría de las especies reportadas para estos yacimientos (Tabla 3) por parte de los grupos cazadores-recolectores de la costa estuarina del Río de la Plata, considerándose bien documentado el uso únicamente de E. mactroides.

\section{Región Oeste}

En la cuenca media y baja del río Uruguay, incluyendo la desembocadura del río Negro se relevan nueve sitios con registros arqueomalacológicos (Figura 1). A nivel general se observa la presencia de un total de 11 taxones de bivalvos y gasterópodos de ambientes dulceacuícolas $(n=7)$, terrestres $(n=2)$ y marinos $(n=2)$ (Tabla 4). Los sitios se encuentran estrechamente vinculados a las líneas de costa fluvial, en cordones litorales arenosos y en elevaciones antrópicas (cf. Edith 1985) en las planicies aluviales (Gascue et al. 2016b, Loponte et al. 2016, Maeso 1977) e 
islas del Uruguay medio y boca del río Negro (e.g. Guidón 1989, Maeso 1977) (Tabla 1). Al igual que lo expuesto para las anteriores regiones del territorio uruguayo, los registros de moluscos se vinculan tanto a los aspectos simbólicos (producción de ornamentos y prácticas funerarias) como a los económicos (consumo alimenticio y producción de artefactos utilitarios) (Tabla 4).

\begin{tabular}{|c|c|c|c|c|c|c|c|}
\hline Sitio & ID Original & $\begin{array}{c}\text { Reidentificación - } \\
\text { Taxón }\end{array}$ & $\begin{array}{c}\mathbf{n} \\
\text { relevado }\end{array}$ & Hallazgo & Estado & Uso & Fuente \\
\hline \multirow{2}{*}{$\begin{array}{l}19 \text { Punta } \\
\text { Chaparro }\end{array}$} & --- & a realizar & $N R=26$ & estratificadd & $\begin{array}{c}\text { modificado } \\
\text { abrasionado y } \\
\text { perforado } \\
\end{array}$ & $\begin{array}{c}\text { ajuar } \\
\text { funerario } \\
\text { (collar) } \\
\end{array}$ & $\begin{array}{c}\text { Col. Fontana; } \\
\text { este trabajo }\end{array}$ \\
\hline & $\begin{array}{c}\text { Valvas de moluscos y } \\
\text { una voluta }\end{array}$ & --- & nd & estratificadd & nd & $\begin{array}{l}\text { consumo } \\
\text { (implícito) }\end{array}$ & Fontana 1928 \\
\hline \multirow{10}{*}{$\begin{array}{l}20 \text { Cañada } \\
\text { Saldaña }\end{array}$} & \multirow[b]{2}{*}{ Diplodon } & Diplodon variabilis & $\mathrm{NR}=88$ & \multirow{10}{*}{ estratificadd } & comp. y frag. & consumo & \multirow{9}{*}{$\begin{array}{c}\text { Maruca Sosa } \\
\text { 1957, Bonino } \\
\text { 1961, Col. } \\
\text { Oliveras; } \\
\text { Este Trabajo }\end{array}$} \\
\hline & & $\begin{array}{c}\text { Diplodon } \\
\text { parallelopipedon }\end{array}$ & $\mathrm{NR}=1$ & & completo & consumo & \\
\hline & --- & Pomacea canaliculata & $N R=5$ & & fragmentadas & $\begin{array}{l}\text { posible } \\
\text { consumo }\end{array}$ & \\
\hline & \multirow{3}{*}{ Anodontites } & $\begin{array}{c}\text { Anodontites } \\
\text { trapesialis }\end{array}$ & $\mathrm{NR}=8$ & & comp. y frag. & consumo & \\
\hline & & Anodontites sp. & $\mathrm{NR}=1$ & & $\begin{array}{l}\text { modificado } \\
\text { perforado }\end{array}$ & ornamental & \\
\hline & & Anodontites sp. & $\mathrm{NR}=23$ & & fragmentados & consumo & \\
\hline & -- & Amiantis purpurata & $\mathrm{NR}=1$ & & completo & $\begin{array}{c}\text { antrópico } \\
\text { desconocido }\end{array}$ & \\
\hline & -- & Glycymeris longior & $N R=2$ & & completo & $\begin{array}{c}\text { antrópico } \\
\text { desconocido }\end{array}$ & \\
\hline & --- & Megalobulimus sp. & $\mathrm{NR}=1$ & & fragmentado & $\begin{array}{c}\text { posible } \\
\text { consumo }\end{array}$ & \\
\hline & Castalia & Castalia sp. & nd & & nd & nd & Bonino 1961 \\
\hline \multirow{6}{*}{$\begin{array}{l}21 \mathrm{La} \\
\text { Blanquea- } \\
\text { da }\end{array}$} & $\begin{array}{l}\text { Barbote en valva de } \\
\text { molusco }\end{array}$ & Diplodon sp. & $\mathrm{NR}=3$ & \multirow{6}{*}{ estratificadd } & $\begin{array}{l}\text { modificado } \\
\text { abrasionado }\end{array}$ & $\begin{array}{c}\text { ornamental } \\
\text { tembetá }\end{array}$ & $\begin{array}{c}\text { Maeso 1977, } \\
\text { Hilbert 1991, } \\
\text { Col. Maeso }\end{array}$ \\
\hline & Valvas diplodón & a realizar & $N R=5$ & & modificado & $\begin{array}{c}\text { 3puntas } \\
\text { proy. } \\
\text { 1ornamento } \\
\text { 1instrumento }\end{array}$ & \multirow{5}{*}{ Maeso 1977} \\
\hline & Valvas de moluscos & a realizar & nd & & nd & $\begin{array}{l}\text { consumo } \\
\text { implícito } \\
\end{array}$ & \\
\hline & Bulimulus & Bulimulus sp. & nd & & nd & nd & \\
\hline & Bonus & Megalobulimus sp. & nd & & nd & nd & \\
\hline & Ampularia & Pomacea sp. & nd & & nd & nd & \\
\hline \multirow{3}{*}{$\begin{array}{l}22 \text { Isla del } \\
\text { Infante }\end{array}$} & --- & Diplodon variabilis & $\mathrm{NR}=4$ & \multirow{3}{*}{ superficial } & $\begin{array}{c}\text { completas y } \\
\text { fragmentadas }\end{array}$ & \multirow{3}{*}{$\begin{array}{l}\text { posible } \\
\text { consumo }\end{array}$} & \multirow{3}{*}{$\begin{array}{c}\text { Col. } \\
\text { Oliveras; } \\
\text { Este trabajo }\end{array}$} \\
\hline & -- & $\begin{array}{c}\text { Diplodon } \\
\text { parallelopipedon } \\
\end{array}$ & $\mathrm{NR}=2$ & & fragmentado & & \\
\hline & -- & Pomacea megastoma & $\mathrm{NR}=1$ & & fragmentado & & \\
\hline 23 El Cerro & Megalobulimus sp. & Megalobulimus sp. & $N R=2$ & estratificadd & completos & $\begin{array}{c}\text { ajuar } \\
\text { funerario }\end{array}$ & $\begin{array}{l}\text { Gascue et al. } \\
2016 \mathrm{~b}\end{array}$ \\
\hline 24 Yaguareté & -- & Diplodon sp. & $\mathrm{NR}=2$ & superficial & fragmentadas & nd & $\begin{array}{c}\text { Col. } \\
\text { MMHNRN }\end{array}$ \\
\hline \multirow{2}{*}{$\begin{array}{c}25 \mathrm{La} \\
\text { Yeguada }\end{array}$} & Bivalvos fluviales & a realizar & \multirow{2}{*}{$\begin{array}{c}\text { nd } \\
\text { lentes }\end{array}$} & \multirow[t]{2}{*}{ estratificadd } & nd & consumo & \multirow{2}{*}{$\begin{array}{c}\text { Boretto 1969, } \\
\text { Loponte et al. } \\
2016 \\
\end{array}$} \\
\hline & Gasterópodos de río & a realizar & & & nd & consumo & \\
\hline $\begin{array}{l}26 \text { Puerto } \\
\text { Viejo }\end{array}$ & ( & $\begin{array}{c}\text { Diplodon } \\
\text { parallelopipedon }\end{array}$ & $N R=3$ & estratificadd & fragmentadas & consumo & este trabajo \\
\hline \multirow{7}{*}{$27 Y-58$} & \begin{tabular}{|c|} 
valvas caracoles \\
dulceacuícolas, \\
terrestre \\
megalobulimus \\
oblongus, almejas de \\
río \\
\end{tabular} & a realizar & nd & estratificadd & comp. y frag. & consumo & Guidón 1989 \\
\hline & Pomacea megastoma & Pomacea megastoma & $\mathrm{NR}=9$ & \multirow{6}{*}{ estratificado } & comp. y frag. & nd & \multirow{5}{*}{$\begin{array}{c}\text { Rosa } \\
\text { Giordano } \\
2011\end{array}$} \\
\hline & Felipponea iheringi & Felipponea iheringi & $\mathrm{NR}=7$ & & fragmentadas & nd & \\
\hline & Megalobulimus sp. & Megalobulimus sp. & $\mathrm{NR}=5$ & & comp. y frag. & nd & \\
\hline & Bullimulus sp. & Bullimulus sp. & $\mathrm{NR}=1$ & & completa & nd & \\
\hline & $\begin{array}{l}\text { Diplodon sp.y/o } \\
\text { Anodontites sp. }\end{array}$ & $\begin{array}{l}\text { Diplodon sp. y/o } \\
\text { Anodontites sp. }\end{array}$ & $\mathrm{NR}=8$ & & fragmentadas & nd & \\
\hline & $\begin{array}{c}\text { caracoles en sepultura } \\
\text { con cierto patrón de } \\
\text { arreglo }\end{array}$ & $\begin{array}{l}\text { Pomacea megastoma y } \\
\text { Felipponea sp. }\end{array}$ & $\begin{array}{c}\mathrm{NR}=1 \\
\mathrm{NR}=10\end{array}$ & & nd & $\begin{array}{c}\text { ajuar } \\
\text { funerario } \\
\text { (sustituyen } \\
\text { al cráneo) }\end{array}$ & $\begin{array}{c}\text { Col. MHS } \\
\text { Guidón } 1989\end{array}$ \\
\hline
\end{tabular}

Tabla 4: Registros arqueomalacológicos en sitios de la región Oeste (litoral fluvial) 
La presencia de moluscos en los ajuares funerarios de la región se ve consustanciada en los sitios El Cerro (Boretto et al. 1973, Gascue et al. 2016b), Punta Chaparro (Fontana 1928) e Y-58 (Guidón 1989). En el primer caso, se trata de dos ejemplares completos de Megalobulimus sp. localizados sobre la parrilla costal de un individuo masculino de aproximadamente 35 años de edad, en posición primaria decúbito dorsal, también acompañado por tres instrumentos líticos pulidos (Gascue et al. 2016b) y un fósil pulido (Félix Bernal com. pers.). En el sitio Punta Chaparro se exhumaron al menos seis individuos entre enterratorios múltiples e individuales (Fontana 1928, 1930, 1951). En el Museo Lucas Roselli de la ciudad de nueva Palmira (departamento de Colonia), se encuentra en exposición uno de estos individuos, desconociéndose a cuál de los anteriores hallazgos corresponde. Este presenta la particularidad de estar expuesto junto a tres placas de cobre y un collar en valvas de molusco, cuyo alto grado de formatización y reducido tamaño de las cuentas imposibilita su identificación taxonómica.

Del sitio Y-58, localizado en la Isla de Arriba, actualmente sumergido por el embalse de la represa de Salto Grande, se recupera material malacológico asociado al cultural en varias excavaciones. En este sitio (excavación IX) se recuperó un individuo en posición extendido decúbito dorsal, cuyo cráneo se encontraba desplazado y fragmentado, y en su lugar se colocó un conjunto de caparazones de gasterópodos (Guidón 1989). El mencionado individuo se encuentra expuesto en el Museo del Hombre y la Tecnología de la ciudad de Salto (departamento de Salto), y a partir de su relevamiento se constató que el conjunto de moluscos se componía por al menos 10 caparazones de Felipponea sp. y uno de Pomacea megastoma. Los fechados radiocarbónicos disponibles sitúan a estos contextos funerarios de los sitios El Cerro e Y-58, en 1910 \pm 50 años AP (Castillo 2004, Gascue et al. 2016b) (Tabla 1), y 2420 \pm 80 años AP (Díaz 1977) respectivamente.

De manera menos clara debido a sesgos descriptivos de la época, se describen moluscos dulceacuícolas (principalmente Diplodon sp.) en asociación a restos humanos para los sitios Campo Morgan y La Blanqueada (Maeso 1977). Sin embargo, por estar generalmente asociados a otros restos de alimentación, su adscripción a los contextos funerarios es difícil de establecer.

Entre los elementos con clara funcionalidad ornamental, se destaca el hallazgo de tres tembetá manufacturados en valva de Diplodon sp. (Figura 5A) recuperados en el sitio La Blanqueada, ubicado en el delta del río Negro (Maeso 1977, Hilbert 1991). Farías (2005) indica que el sitio presenta cronologías de 1760-1150 años AP (Tabla 1). Estos tembetá si bien comparten un patrón morfológico similar, presentan variaciones en relación a su tamaño y diseño (relación eje vertical y sección transversal), que en el caso del tembetá No 3 (Figura 5A) podrían vincularse a una etapa de formatización avanzada, pero no concluida. Elementos extremadamente similares han sido hallados en sitios de la margen derecha del río Uruguay (Bonomo et al. 2014) y en el Delta del Paraná inferior en cinco sitios (Las Vizcacheras, Punta Canal, El Cazador 3, Cerro Lutz, Guazunambí y La Bellaca 1) (Acosta et al. 2015, Loponte 2008) asociados, excepto en 
Punta Canal, a contextos cazadores-recolectores con cerámica sin decoración (Loponte 2008). Esto representa un aspecto diferente respecto a la asociación material de los tembetá confeccionados en valva de molusco en el litoral oriental, ya que el sitio La Blanqueada presenta diversos elementos diagnósticos (incluidos apéndices zoomorfos y campanas) que han conducido a adscribirlo a la cultura de los Ribereños Plásticos (ver Hilbert 1991) o Goya-Malabrigo (ver Gascue et al. 2016b). En virtud de las limitaciones, ya mencionadas respecto a los registros de Maeso, el contexto inmediato de hallazgo de los materiales es muy difícil de determinar. Sin embargo, uno de estos tembetá fue hallado junto a las vértebras cervicales de un enterratorio de un individuo adulto en posición decúbito dorsal, junto a un gancho de propulsor óseo y un número no determinado de "valvas perforadas" (Maeso 1977: 186), sumando información adicional acerca de la valoración simbólica de estos elementos por parte de estos grupos humanos.

Precisamente, las evidencias del uso ornamental de los moluscos en el litoral oriental del río Uruguay se completa con los hallazgos reportados por Maeso (1977) de diversas valvas perforadas y otros artefactos referidos como adornos y amuletos, que podrían relacionarse con la producción de cuentas y otros ornamentos personales. Asimismo, ello se suma a los objetos de este tipo confeccionados en piedras verdes y cobre, que han sido recuperados en La Blanqueada y otros sitios de la región (Farías et al. 1997, Figueira 1892, Hilbert 1991, Maeso 1977). También, para el sitio Bañadero, ubicado en el albardón costero frente a la isla del Medio, en Salto Grande, la MRASG reporta el hallazgo de cuentas de collar elaboradas sobre valvas (Guidón 1989).

En la colección Oliveras, se relevó una valva de Anodontites sp. con una perforación antrópica, recuperada en los trabajos de excavación realizados en la década de 1950 en el sitio Cañada Saldaña (Figura 5B). Este artefacto es ilustrativo del proceso de manufactura de las cuentas en valva de molusco, ya que sus características morfológicas sugieren que se trata de una preforma, donde partiendo de un fragmento de valva primero se realiza el orificio y posteriormente se concluiría la formatización de la cuenta por abrasión. Existen también varias referencias (Acosta et al. 2015, Bonomo 2012, Outes 1917) que muestran la utilización de especies tanto locales (dulceacuícolas) como marinas (e.g. U. haneti y G. longior) orientadas a la producción de cuentas, en la región litoral.

La producción de artefactos utilitarios vinculados a la esfera tecno-económica de los cazadores recolectores ceramistas permanece escasamente documentada. Las únicas referencias al respecto fueron brindadas por Maeso (1977) quien describe algunos artefactos como punzones manufacturados con la "voluta" (columela?) de gasterópodos y una punta de proyectil en valva de Diplodon sp., ambos para el sitio La Blanqueada, que no han podido ser a la fecha localizados en la colección.

También se identificaron conchillas sin modificaciones tecnológicas de diversas especies fluviales (Diplodon variabilis, Diplodon parallelopipedon, Anodontites trapesialis, 
Castalia sp., Pomacea canaliculata, Pomacea megastoma, y Felipponea iheringi), terrestres (Megalobulimus sp. y Bulimulus sp.) y marinas (Amiantis purpurata y Glycymeris longior) en contextos domésticos de ocho sitios litorales con cronologías entre 2420 y 510 años AP (Figura 1; Tabla 1 y 4). Tanto las dulceacuícolas (dominadas ampliamente por Diplodon sp.) como las terrestres han sido por los diversos autores vinculadas implícita o explícitamente al consumo humano (e.g. Bonino de Langguth 1961, Guidón 1989, Maeso 1977, Maruca Sosa 1957).
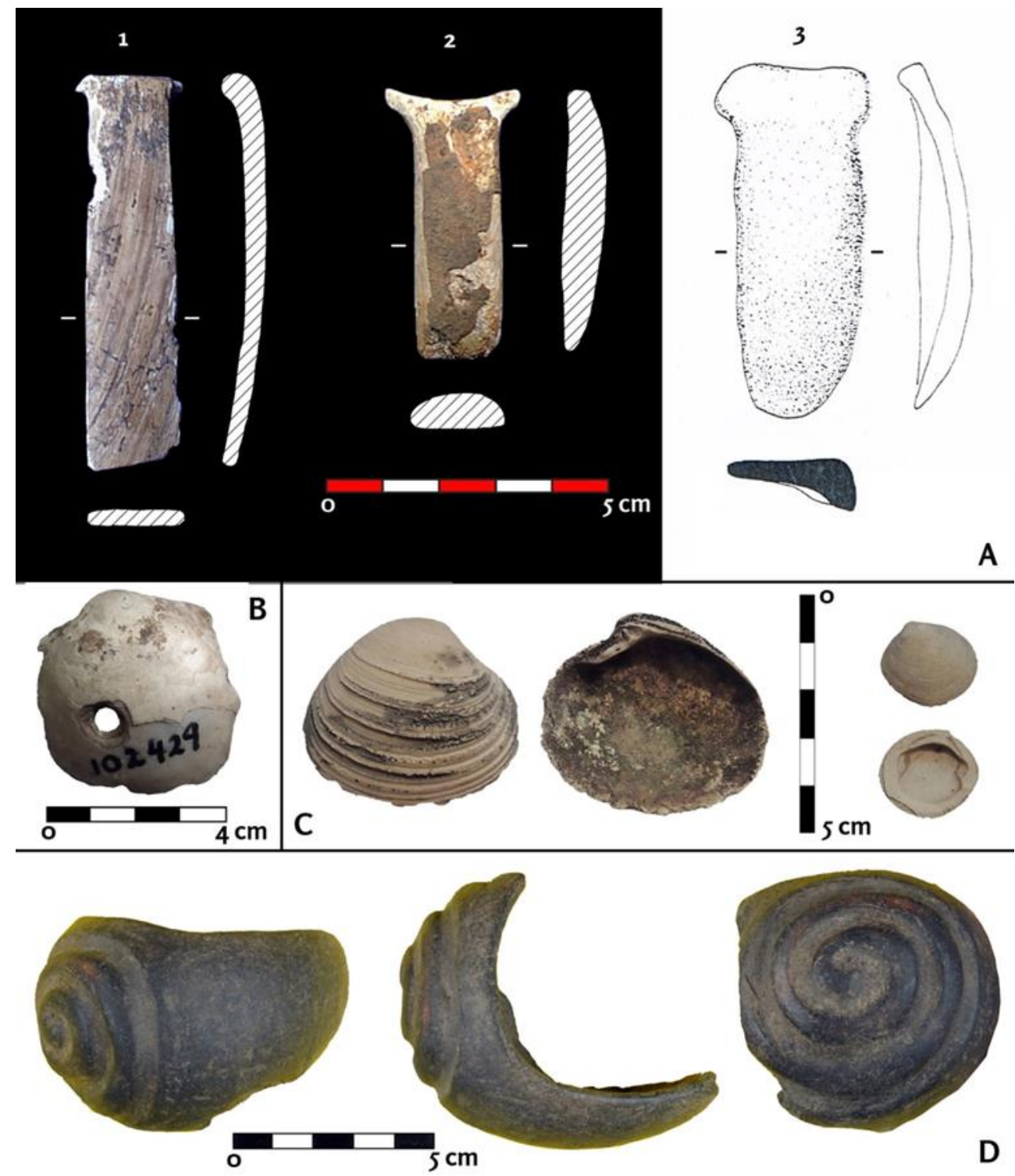

Figura 5: A) Tembetás recuperados en sitio La Blanqueada, colección Maeso (composición realizada a partir de fotografías, e ilustraciones tomadas y modificadas de Hilbert (1991); B) Fragmento de valva de Anodontites sp. perforada desde cara externa del sitio Cañada Saldaña (colección Oliveras; Museo Nacional de Antropología); C) Valvas completas sin modificación antrópica de A. purpurata y G. longior, sitio Cañada Saldaña (colección Oliveras; Museo Nacional de Antropología); D) Fragmento de vasija pequeña con morfología y decoración atribuible a un gasterópodo, sitio La Yeguada (colección Museo Municipal de Historia Natural de Río Negro). 
En cuanto a las especies marinas, únicamente identificadas para el sitio Cañada Saldaña (Figura 5C) se trata de los primeros registros de especies de este tipo, sin modificación, en contextos arqueológicos del litoral oriental. Por su escasa presencia $(\mathrm{n}=2)$ y su carácter transportado desde cientos de $\mathrm{km}$ de distancia, son en esta oportunidad catalogadas como de origen antrópico desconocido. Sin embargo, su transporte y utilización ha sido bien documentado en la margen occidental del río Uruguay (Acosta et al. 2015) por lo cual es posible que estas piezas hayan sido conservadas como reservorio de materia prima o por algún tipo de valoración simbólica particular.

En relación directa con la importancia que significaron los moluscos en la economía de los grupos cazadores-recolectores del litoral fluvial uruguayo, es destacable que la mayor cantidad de registros corresponde a un patrón disperso. Solo se describen patrones agrupados, bajo la forma de lentes gruesos, para el sitio La Yeguada (Boretto 1969) y para el sitio Y-58 caracterizado por la presencia de "caracoleras" (Guidón 1989). Para este último, se describe en la excavación I presencia de caracoles terrestres y fluviales formando capas compactas entre 0-30 $\mathrm{cm}$ de profundidad, y se describen fosas culinarias entre los 58 y $66 \mathrm{~cm}$. Para la excavación II se mencionan caracoleras que van desde el tope a los $85 \mathrm{~cm}$ dispuestos "formando montículos, y situados, en la mayor parte de los casos, en una concavidad conteniendo cenizas y carbones y recubiertos por arena limpia" (Guidón 1989:162). Posteriores análisis, de una muestra no representativa $(n=30)$ de estos elementos malacológicos, posibilitó identificar tres especies dulceacuícolas (dos gasterópodos y un bivalvo) y dos gasterópodos terrestres (Rosa Giordano 2012) (Tabla 4) que contribuyeron a una mejor caracterización del abanico de especies explotadas en este yacimiento. Si bien se trata de los registros más significativos del litoral fluvial uruguayo, los trabajos al respecto son aún escasos y fragmentarios, requiriendo su profundización a futuro.

La información recabada para esta región, al igual que en las anteriormente descritas, sugiere que los recursos malacológicos, si bien fueron objeto de consumo alimentario, tuvieron un rol relativamente menor en las dietas de estos grupos cazadores recolectores (ver también al respecto Acosta et al. 2017) donde en general se presentan en un patrón disperso mezclados con numerosos restos de alimentación correspondientes mayoritariamente a vertebrados. Sin embargo, el conjunto de evidencias a nivel regional muestra que la malacofauna tuvo un papel relevante en los aspectos simbólicos de estas culturas, ya que reiteradamente forman parte de los rituales funerarios, y se constituyen como elementos de comunicación intra e inter grupo a partir de su utilización en la producción de ornamentos, llegando incluso a estar representados en la tecnología cerámica, como en el sitio Goya-Malabrigo de La Yeguada (Loponte et al. 2016) (Figura 6D) y Campana (Politis y Bonomo 2015: 170). 


\section{Consideraciones finales}

La escasa interacción malacología-arqueología durante décadas implicó una cierta invisibilidad y una limitada interpretación del registro arqueomalacológico en Uruguay. No obstante, la síntesis efectuada en el presente trabajo muestra que si bien estos registros no son sustanciales en relación a la gran cantidad de sitios investigados a la fecha, su uso ha sido frecuente y diverso por parte de los grupos cazadoresrecolectores del territorio uruguayo durante el Holoceno tardío.

Consumo alimentario de moluscos

La información discutida en este trabajo indica que, si bien existieron estrategias orientadas a la explotación económica (subsistencia) de moluscos (a diferencia de áreas vecinas como la costa pampeana; ver Bonomo 2007) éstas se limitaron a un reducido número de especies en relación al total de taxones registrados en los 27 sitios aquí considerados. Por ejemplo, para la costa atlántica, de las 22 especies registradas en los sitios, tan solo tres pueden ser vinculadas sin lugar a dudas al consumo humano; estas son las marinas $D$. hanleyanus (con amplia representación en los concheros de La Esmeralda), marginalmente O. auricularia, y la terrestre A. lutescens, registrada en el depósito antrópico de la playa sur de Cabo Polonio. Por otra parte en la costa estuarina únicamente E. mactroides presenta evidencias de haber sido objeto de consumo. La zona litoral fluvial presenta gran disponibilidad y accesibilidad de moluscos en el entorno inmediato a los sitios (Olazarri 1980) pero, su escasa presencia y carácter disperso en la mayoría de los yacimientos podría indicar un consumo marginal por parte de los grupos prehispánicos. Se destaca $D$. variabilis por sus mayores frecuencias relativas tanto a nivel nacional como en los sitios de Argentina (Loponte y Acosta 2017). Para los sitios Y-58 (Departamento de Salto) y CH2D01 (Departamento de Rocha), si bien se propone el consumo alimenticio de especies de bivalvos y gasterópodos dulceacuícolas y terrestres, las características de los registros dificultan ponderar el alcance económico de los moluscos, requiriendo relevar en profundidad estas colecciones. Contextos similares se han descrito a nivel regional, para los sitios Cerro Chico I y Los Sauces II (Bonomo et al. 2014), Cerro Lutz (Loponte 2008) y Puerto Landa (Greslebin 1931). No obstante, es de destacar que en ambos casos uruguayos donde se registra una mayor intensidad en el consumo de moluscos (La Esmeralda e Y-58) sus cronologías los vinculan a períodos ambientales caracterizados por una mayor aridez (Inda et al. 2011), lo que refuerza el carácter de recurso consuelo, utilizado para amortiguar momentos de estrés ambiental y posiblemente alimenticio.

Por otra parte, las limitaciones impuestas por ambientes micromareales marinos y estuarinos puede contribuir a explicar la baja incidencia en el consumo de moluscos detectado a nivel regional. De hecho, varias de las especies registradas en los sitios (e.g. A. purpurata, G. longior, P. brasiliana, B. cochlidium) viven a profundidades inaccesibles sin aplicar técnicas de buceo. Si bien tormentas y eventos de baja salinidad generan condiciones puntuales en las que algunas especies quedan accesibles en las playas con las partes blandas y aptas de ser consumidas (e.g. López et al. 2008, Scarabino et al. 
2016b), las bajas frecuencias en los sitios no apuntan a una selección sistemática de estos moluscos para su consumo. Para Rio Grande do Sul, Osório Rosa (2006: 255) indica: "É bastante provável que algumas conchas marinhas, sobretudo de Adelomelon brasilana, tenham sido coletadas vazias apenas para servirem de matéria prima para a confecção de instrumentos, como raspadores, alisadores, perfuradores, entre outros". Para las especies mencionadas, el conjunto de evidencias apunta a la recolección de conchillas y valvas vacías y, que la misma se vincula a factores asociados a su valor simbólico, y en menor medida a la producción de instrumentos utilitarios. Esto lo testimonia su presencia en enterratorios humanos y su participación en redes de intercambio a cortas y grandes distancias como se desprende de su presencia en cerritos de indios y en el sitio Cañada Saldaña (ver también al respecto Acosta et al. 2017, Bonomo 2007).

Uso simbólico de los moluscos

De acuerdo a que la mayoría de las especies de moluscos registradas en contexto arqueológicos en Uruguay no habrían sido aprovechadas desde el punto de vista alimenticio, se propone que el rol preponderante de los mismos se asocia a los aspectos simbólicos, situación similar a la referida para la región pampeana (ver Acosta et al. 2017, Bonomo 2007, 2011). Precisamente, en todas las regiones aquí consideradas habría primado esta función, representada por 10 especies que fueron utilizadas para la confección de ornamentos personales (Conus lemniscatus, Urosalpinx haneti, Olivancillaria auricularia, Olivancillaria urceus, Agathistoma patagonicum, Diodora patagonica, Costoanachis sertulariarum, Ostrea puelchana, Anodontites sp. y Diplodon parallelopipedon) y cinco se encontrarían representadas en los rituales funerarios tanto modificadas como cuentas (Urosalpinx haneti) así como bajo la forma de ecofactos (Glycymeris longior, Diplodon sp., Felipponea iheringi, Pomacea megastoma y Megalobulimus sp.). Los objetos ornamentales han sido explicados como una respuesta ante la creciente complejidad social, económica y demográfica cumpliendo funciones de comunicar información emblemática sobre adscripción étnica, jerarquía o rol social de los individuos, diferenciación por género y connotaciones rituales (ver Acosta et al. 2015 y bibliografía allí citada). A partir de su presencia en contextos funerarios, es posible que estos objetos y significados fueran en algunos casos, también utilizados con fines políticos para marcar el traspaso de alguno de estos atributos sociales hacia los individuos vivos emparentados con los muertos durante los rituales de enterramiento (Brown 1981, Dillehay 1991).

Para el área que nos ocupa, se aprecia el aprovechamiento para estos fines de un diverso abanico de especies, principalmente acuáticas. Las especies terrestres, si bien parecen haber tenido un rol de menor importancia, en el caso de Megalobulimus sp. han sido objeto de valoración simbólica a nivel nacional (como se aprecia en el contexto funerario del sitio El Cerro) y suprarregional dados los hallazgos en contextos similares en el centro y noroeste argentino, y norte de Chile, bajo la forma de ecofactos y cuentas (Boretto et al. 2018, Ortiz y Vargas 2015). 
La mayoritaria ocurrencia de especies acuáticas dentro del uso simbólico podría estar en directa relación con la importancia de estos ambientes (y seguramente de los recursos en ella contenidos) para la vida de estos grupos. En el mismo contexto se debe señalar que el vínculo de las comunidades indígenas del litoral del río Uruguay con los moluscos, parece haber sido tan profundo que quedó grabado en el topónimo del propio río. En este sentido, la palabra Uruguay, de origen Guaraní, tiene por significado río de los caracoles (Granada 1957, Peralta 1950). Así quedó registrado por los jesuitas, primeros europeos que tuvieron contacto y registraron la etimología de la toponimia de la región. El padre Nicolás Mastrillo Durán S.J. en su décima carta annua señala que uruguay significa "agua de caracoles, por la gran abundancia que ay dellos en sus riveras" mientras que el padre Antonio Ruiz de Montoya S.J. traduce uruguá como caracol de agua, e $i$ como agua o río (Ruiz de Montoya 1639: 407/163). También el padre José Sánchez Labrador S.J. en el inédito libro "El Paraguay Natural" indica que el río Uruguay o río de los caracoles se llama así por los caracoles que se hallan en sus orillas, algunos del tamaño de un puño y que los indios asaban en su propia cáscara y luego los comían (tomado de Soares de Lima 2007: 27). En referencia a qué caracol daría el nombre al río Uruguay tanto Alcides d'Orbigny (1835) en su libro de viaje por América Meridional, como Juan Zorrilla de San Martín (1956) en su obra Tabaré, hacen referencia a "ampullarias". Estas últimas, son gasterópodos que pertenecen a la familia Ampullariidae que en Uruguay está representada por 10 especies (Scarabino 2004b). Tres de ellas alcanzan el citado "tamaño de un puño" las tres pertenecientes al género Pomacea: Pomacea canaliculata, P. maculata y P. megastoma. En particular, como se ha referido anteriormente en este trabajo y en Doello Jurado (1917), P. megastoma ha sido registrada asociada a enterramientos humanos y en caracoleras en la zona de Salto Grande e Isla Martín García. No menor es el hecho de que $P$. megastoma es una especie endémica del río Uruguay, los cursos bajos de sus afluentes y la margen izquierda del río de la Plata hasta Colonia del Sacramento (Clavijo y Scarabino 2013, Clavijo et al. 2008).

Redes de intercambio de moluscos

La presencia de moluscos marinos en sitios de Argentina ubicados en el Delta del Paraná, Córdoba, San Luis, Mendoza, Santiago del Estero y Tucumán (e.g. Acosta et al. 2017, Doello-Jurado 1940, Outes 1917) ha sido explicada a partir de la existencia de extensas redes de intercambio en las que participaron los objetos en cobre, rocas verdes, recursos minerales aptos para la talla, moluscos marinos donde $U$. haneti fue objeto de un transporte más extenso- y en época histórica las cuentas de vidrio (Acosta et al. 2015, 2017, Bonomo et al. 2017, Castro 2017, DoelloJurado 1940, Torres 1911). Respecto a las fuentes de aprovisionamiento de los moluscos marinos, el debate no ha sido resuelto, proponiéndose que los mismos se captaron en depósitos de playa y/u holocénicos (subfósiles) de la costa pampeana, sureste de Entre Ríos y/o del litoral atlántico uruguayo (e.g. Acosta et al. 2017, Bonomo 2007, Doello-Jurado 1940, Martínez Soler 1959, Outes 1917). Los datos aquí sintetizados para el territorio uruguayo, indican que la ruta uruguaya de los moluscos marinos (con y sin modificaciones) está bien documentada a partir de los 
hallazgos de $O$. urceus, $U$. haneti, $C$. sertulariarum y $D$. patagonica en al menos tres sitios de la costa del Río de la Plata (Piedras de Afilar, Arazatí y San Gregorio) y de G. longior y A. purpurata en el litoral (sitio Cañada Saldaña). Por otra parte, se confirma un transporte a menores distancias hacia espacios interiores del departamento de Rocha caracterizado por los hallazgos de O. puelchana, A. patagonicum, P. brasiliana y otras que se repiten (G. longior y U. haneti) en cerritos de indios y sitios adyacentes a ellos. Sin descartar el origen argentino de estos materiales, entendemos que la evidencia uruguaya excede el escenario de "lo posible".

En este contexto de intercambios supra-regionales e interculturales de objetos y recursos exóticos realizados a partir del Holoceno tardío, las redes de comercio podrían haber sido estructuradas en al menos dos etapas. Dentro del territorio uruguayo puede proponerse que los moluscos marinos arriban a la zona litoral a partir del trueque por ejemplo de rocas como caliza silicificada y calcedonia disponibles en las cuencas del Santa Lucía y Uruguay, y presentes en muy bajas proporciones en sitios y niveles cerámicos de la región Este (ver López Mazz y Gascue 2007, López Mazz et al. 2010). Posteriormente, a través de los ríos Paraná y Uruguay, los moluscos entrarían al circuito del cobre y piedras verdes, alcanzando así el noroeste argentino. En ambos casos, las cantidades en que se hallan cada uno de los elementos mencionados en las distintas zonas, parecen ser compatibles con la relación de proporcionalidad de los intercambios propuesta a nivel teórico (ver Foladori y Melazzi 2009:40).

A partir de la síntesis presentada es indudable que aún faltan elementos para evaluar integralmente el rol de los moluscos para los grupos cazadores-recolectores que habitaron el actual territorio uruguayo durante el Holoceno tardío. En este sentido, y como perspectivas futuras consideramos fundamental: profundizar el relevamiento de colecciones y acervos existentes a nivel nacional, basados en la interacción arqueología-malacología; aplicar técnicas actuales para la recuperación y conservación de las muestras arqueomalacológicas (ver Storch 1997); y profundizar el estudio de los materiales y/o sitios significativos para el registro arqueomalacológico uruguayo como es el caso de los sitios La Esmeralda, Y-58 y los de la cuenca del río Santa Lucía. Estos puntos permitirán sin dudas ampliar el esquema aquí sintetizado así como contribuir a la conservación de este registro dentro de las colecciones.

Agradecimientos: a Carina Erchini, Alejandro Ferrari y Marcela Tobella del Museo Nacional de Antropología; Jorge Frogoni del Museo Lucas Roselli y al Municipio de Nuevo Berlín, por su colaboración durante el relevamiento de las colecciones. A Jorge Baeza, Félix Bernal, Lilian Cardoso, Alvar Carranza, Laura del Puerto, Felipe GarcíaRodríguez, Hugo Inda, Camila Gianotti, Diego Ronchera y Eugenia Villarmarzo por el apoyo general y/o en aspectos particulares relevantes a este trabajo. Cualquier omisión o error que contenga este trabajo es exclusiva responsabilidad de los autores. 


\section{Notas}

${ }^{2}$ Conus lemniscatus es una especie de rara ocurrencia en la costa atlántica uruguaya cuya presencia en el registro arqueológico implicaría una selección intencional por parte de los grupos debido a su forma particular.

${ }^{2}$ Respecto a la identificación original de las especies presentada en las tabla 2 a 4 corresponden algunas aclaraciones. La denominación de las especies depende de la investigación que exista sobre ellas así como de aspectos puramente formales (nomenclatura, gramática). El avance de la investigación y del tratamiento de estos aspectos formales y su consideración o no, implica variaciones dentro de algunos márgenes, que a veces inclusive resultan excedidos. Cabe destacar que: 1) para los epítetos específicos donde se dedican especies a personas era válido hasta principios del siglo XIX el uso de mayúsculas y no lo es actualmente, 2) que el autor y año de una especie se escribe entre paréntesis solo si no se usa la grafía -combinación de género y epíteto específico original- $y, 3$ ) no se utiliza ningún tipo de acento en nomenclatura taxonómica (ver CINZ 2000). Así, Urosalpinx haneti (Petit de la Saussaye, 1856) es considerado actualmente como sinónimo senior (anterior) de Urosalpinx rushii Pilsbry, 1897 (a su vez descrito como Urosalpinx Rushii y enmendado injustificadamente como Urosalpinx rushi). Por dinámicas que deben mejorarse tanto en arqueología como en malacología, la literatura arqueomolacológica se ve particularmente afectada en relación a la denominación de las especies. Tomando dicha especie como ejemplo, se llega al extremo de denominarla "Uroxalping.laeta" (ver Lagiglia, 2009). A su vez, Urosalpinx haneti es considerado por algunos autores como perteneciente a otro género (Hanetia), denominándose entonces en forma alternativa Hanetia haneti. Casos similares a la asignación a uno u otro género ocurren con Pachycymbiola brasiliana (vs. Adelomelon brasiliana), Agathistoma patagonicum (vs Tegula patagónica) y Diplodon variabilis (vs. Rhipidodonta variabilis). La base de datos Worms (World Register of Marine Species, http://www.marinespecies.org/), es una excelente guía para acercarse a la historia taxonómica de las especies acuáticas (y su denominación actual).

${ }^{3}$ Cabe señalar que el fechado corresponde a los niveles inferiores del sitio (unicomponente) y los restos de Stramonita brasiliensis provienen de los niveles superiores, por lo cual podrían corresponder a una fecha posterior.

\section{Bibliografía citada}

Acosta, A.; N. Buc; M. Davrieux

2015 Producción y uso de ornamentos en las tierras bajas de Sudamérica: el caso de las poblaciones humanas prehispánicas del extremo meridional de la cuenca del Plata (Argentina). Munibe Antropologia-Arkeologia 66: 309-325.

Acosta, A.; G. Pastorino; D. Loponte 2017 Registro de moluscos marinos entre cazadores-recolectores del norte de la región Pampeana. Comechingonia (21) 1: 233-259. 
Arechavaleta, J.

1892 Viaje a San Luis. El Uruguay en la Exposición Histórica-Americana de Madrid. Memoria de los trabajos realizados por la Comisión Nacional encargada de organizar los elementos de concurrencia, pp. 65-106. Imprenta Artística Dornaleche y Reyes, Montevideo.

Ayup, $\mathrm{N}$

1991 Avaliação das Mudanças do Nivel do Mar Durante o Holoceno na Plataforma Continental Adjacente ao Río de la Plata. Tesis doctoral. Universidad Federal de Río Grande do Sul, RGS.

Baeza, J.; A. Bosch; J. Femenías; M. Moreno; M. Pinto; S. De Pinto 1980. Informe sobre la Zona Costera Atlántica de Cabo Polonio-Balizas ( $2^{\mathrm{a}}$ parte). Actas III Congreso Nacional de Arqueología-IV Encuentro de Arqueología del Litoral, sin paginar. Centro de Estudios Arqueológicos, Montevideo.

Balbo, A.; M. Madella; I. Briz Godino; M. Álvarez

2011 Shell midden research: An interdisciplinary agenda for the Quaternary and Social Sciences. Special issue of Quaternary International 239: 1-6.

Bejega, V.; E. González Gómez De Agüero; C. Fernández Rodríguez

2010 La Arqueomalacología: una introducción al estudio de los restos de moluscos recuperados en yacimientos arqueológicos. Iberus 28 (1): 1-10.

Beovide, L.

2007 Un aporte al conocimiento del cambio climático holocénico desde la investigación arqueológica en el tramo medio del Río de la Plata (Uruguay). Semana de reflexión sobre cambio climático y variabilidad climática, pp. 110-121. Facultad de Agronomía, Montevideo.

2009 Transformaciones productivas y dinámica costera: Más allá del concepto de cazadores-recolectores prehispánicos. XXII Simposio de Investigaciones Arqueológicas en Guatemala (ed. por J.P. Laporte, B. Arroyo y H. Mejía), pp252-266). Museo Nacional de Arqueología y Etnología, Guatemala.

2010 La presencia humana en el curso medio del Río de la Plata (Uruguay) durante el Holoceno medio-reciente: una perspectiva de la continuidad y el cambio. Arqueología Argentina en el Bicentenario de la Revolución de Mayo (ed. por R. Bárcena y E. Chiavazza), pp. 333-334. INCIHUSA, Mendoza.

2011 La presencia de cultígenos desde el quinto milenio en el registro del curso medio Platense: revisión y proyecciones. Avances y perspectivas en la Arqueología del Nordeste (ed. por R. Feuillet, M.B. Colasurdo, J. Sartori y S. Escudero),pp. 155-173). Servicios Gráficos,Buenos Aires.

2013 Concheros en la costa uruguaya del Río de la Plata: una aproximación a la explotación y uso de moluscos por las sociedades de fines del Holoceno Medio. Cuadernos del Instituto Nacional de Antropología y Pensamiento Latinoamericano, Series Especiales 1 (1): 136-148.

2015 Paleopaisajes, territorios, y redes de interacción entre las sociedades Platenses del Holoceno medio-reciente: aportes arqueométricos. En Nuevos aportes de las técnicas de arqueometría en el estudio y caracterización del patrimonio cultural de Latinoamérica (coord. por R. Esparza López), pp. 203-225. El Colegio de Michoacán, Zamora. 
Beovide, L. y S. Campos

2015 El manejo del entorno vegetal y cultígenos (Zea mays) en los concheros entre ca. 3.000 y 2.000 años AP en la cuenca inferior del Río Santa Lucía. Cuadernos del Instituto Nacional de Antropología y Pensamiento Latinoamericano - Series Especiales (2) 4: 56-70.

Beovide, L. y M. Lorenzo

2014 Caracterización de tres tipos de adornos en valvas de moluscos en la prehistoria del Río de la Plata: huellas de las técnicas de producción. Libro de Resúmenes IV Congreso Latinoamericano de Arqueometría, pp. 81-82. Ciudad de México.

Beovide, L. y M. Malán

2003 Arqueología en los humedales costeros del Sur, Uruguay. XII Congreso de la Sociadad de Arqueologia Brasilera, CD ROM. SAB, San Pablo.

2006 Procesos posdepositacionales y disposición espacial de los materiales arqueológicos del sitio Colonización, San José, Uruguay. En Poblemáticas de la arqueología contemporánea (comp. por A. Austral y M. Tamagnini), Tomo I, pp. 283-294. Universidad Nacional de Río Cuarto, Río Cuarto.

Beovide, L. y S. Martínez

2014 Concheros arqueológicos en la costa uruguaya: Revisión y perspectivas. Revista Chilena de Antropología (29) 1: 26-31.

Beovide, L.; S. Martínez; G. Figueiro

2015b Urosalpinx haneti (Gastropoda) como adorno funerario (ca. 900a 500 años ap) Arazatí, costa del Río de la Plata (Uruguay). http://www.octeventos.com/wpcontent/uploads/2017/11/00037_090744_Beovide-Martínez-Figueiro.pdf. (Acceso: 11 de julio, 2018).

Beovide, L.; S. Martínez; W. Norbis

2015a Discriminación entre acumulaciones de moluscos naturales, antrópicas modernas y arqueológicas, constituídas por las mismas especies. Cuadernos del Instituto Nacional de Antropología y Pensamiento Latinoamericano - Series Especiales 4 (2): 21-37.

Beovide, L.; S. Martínez; W. Norbis

2017 Space use patterns and resource explotation of shell middens from the Río de la Plata coast (ca. 6000-2000 years BP). En Uruguay.Zooarchaeology in the neotropics (ed. por M. Mondini, S. Muñoz y P. Fernández), pp. 81-101. Springer, Cham.

Bonino de Languth, $\mathrm{V}$

1961 Los primitivos habitantes del Uruguay y el uso de los moluscos en su economía, en su decoración y en sus ritos. Comunicaciones de la Sociedad Malacológica del Uruguay 1: 11-14.

Bonomo, $\mathrm{M}$.

2004 Ocupaciones humanas en el litoral marítimo pampeano: un enfoque arqueológico. Tesis doctoral. Universidad Nacional de La Plata. La Plata.

$2007 \mathrm{El}$ uso de los moluscos marinos por los cazadores-recolectores pampeanos. Chungará 39 (1): 87-102.

2011 The use of the Space in the Pampean Atlantic Coast and the Adjacent Plains (Argentina, South America): A Comparative View. En Trekking the Shore: Changing 
Coastlines and the Antiquity of Coastal Settlement (ed. por N. Bicho, J. Haws y L. Davis), pp. 333-353. Springer, Nueva York.

2012 Historia Prehispánica de Entre Ríos. Fundación de Historia Natural Félix de Azara, Buenos Aires.

Bonomo, M. y M. Aguirre

2009 Holocene molluscs from archaeological sites of the Pampean Region of Argentina: approaches to past human uses. Geoarchaeology 24 (1): 59-85.

Bonomo, M.; E.D. Cabanillas; R. Montero

2017 Archaeometallurgy in the Paraná Delta (Argentina): composition, manufacture, and indigenous routes. Journal of Anthropological Archaeology 47: 1-11.

Bonomo M.; G. Politis; J. C. Castro

2014 Los indígenas de Entre Ríos. Ministerio de Cultura y Comunicación de la provincia de Entre Ríos, Manual de Entre Ríos, Tomo I, pp. 45-75. Editorial de Entre Ríos, Paraná.

Boretto, G.; S. Gordillo; A. Izeta; F. Colombo; M. Martinelli; R. Cattáneo

2018 Cuentas ornamentales en un contexto de cazadores-recolectores de la provincia de Córdoba: análisis mineralógico y microestructural de la concha de "Borus". Arqueología 24(1): 213-223.

Boretto, R.

1969 Excursión a Nuevo Berlín. Informe preliminar. Boletín del Museo Municipal de Historia Natural de Río Negro,Fray Bentos.

Boretto, R.; R. Bernal; P.I. Schmitz; I. Basile Becker

1973 Arqueología del Departamento de Río Negro (R. O. del Uruguay). Esquema tentativo de una secuencia cronológica para sitios del río Uruguay y Río Negro. Anales del Primer Congreso Nacional de Arqueología Uruguaya, sin paginar. Museo Municipal de Historia Natural de Río Negro, Fray Bentos.

Bossi, J. y L. Ferrando

2001 Carta geológica del Uruguay. Escala 1: 500.000. V 2.0, Geoeditores, Montevideo.

Bowdler S.

2006 Mollusks and other shells. Archaeology in Practice. En A Student Guide to Archaeological Analyses (ed. por J. Balme y A. Paterson), pp.317-337. Blackwell Publishing, New Jersey.

Bracco, R.

1992 Investigaciones arqueológicas de rescate en la cuenca de la Laguna Merin. Biblos 4: $35-42$.

Bracco, R.; L. Cabrera; J. López Mazz

2000 La prehistoria de las tierras bajas de la cuenca de la Laguna Merín. En Arqueología de las tierras bajas (ed. por A. Durán y R. Bracco), pp. 13-38. Ministerio de Educación y Cultura, Montevideo. 
Bracco, R.; D. Panario; C. Ures

1999 Dataciones ${ }^{14} \mathrm{C}$ y efecto reservorio para el litoral del Uruguay. En Actas de las Primeras Jornadas del Cenozoico en Uruguay, sin paginar. Facultad de Ciencias, Montevideo.

Brown, J.

1981 The Search for Rank In Prehistoric Burials. En The Archaeology of Death (ed. por Chapman, Kinnes y Randsborg), pp. 25-37. Cambridge University Press, Cambridge.

Cabrera, L.; A. Durán; J. Femenías; O. Marozzi

2000 Investigaciones arqueológicas en el sitio CG14E01 (Isla Larga) Sierra de San Miguel. Depto Rocha, Uruguay. En Arqueología de las tierras bajas (ed. por A. Durán y R. Bracco), pp. 183-194. Ministerio de Educación y Cultura, Montevideo.

Capdepont, I.; C. Castiñeira; L. del Puerto; G. Fernández

2016 Desarrollo de las ocupaciones humanas durante el Holoceno en la cuenca de la Laguna de Castillos (Uruguay): Síntesis y actualización de las investigaciones arqueológicas. Tessituras (4) 1: 53-93.

Carranza, A; F. Scarabino; L. Ortega

2008 Distribution of large benthic gastropods in the Uruguayan continental shelf and Río de la Plata estuary. Journal of Coastal Research 24: 161-168.

Castillo A.

2004 Excavaciones y museo: Profundizando en el conocimiento de los grupos ceramistas del litoral (Río Negro, Uruguay). En La Arqueología uruguaya ante los desafíos del nuevo siglo (ed. por L. Beovide, I. Barretto y C. Curbelo), CD ROM. Asociación Uruguaya de Arqueología, Montevideo.

Castiñeira, C.; D. Panario; R. Bracco; O. Gutiérrez

2007 Concheros en la costa atlántica uruguaya y su vinculación con la dinámica litoral. En Arqueología Argentina en los inicios de un nuevo siglo (comp. por F. Oliva, N. de Grandis y J. Rodríguez), Tomo 3, pp. 635-643. Laborde Libros, Rosario.

Castro, JC.

2017 Investigaciones arqueológicas en la cuenca media e inferior del río Uruguay (provincia de Entre Ríos). Tesis Doctoral. FCNyM-UNLP, La Plata.

CINZ

2000 Código Internacional de Nomenclatura Zoológica. Cuarta edición. Museo de Ciencias Naturales, Madrid.

Clavijo, C.; A. Carranza; F. Scarabino

2008 Distribution of Pomella megastoma (Sowerby, 1825) (Gastropoda: Ampullarii “ ' En Libro de resúmenes VII Congreso Latinoamericano de Malacología, pp. 251. Valdivia.

Clavijo C. y F. Scarabino

2013 Moluscos continentales. Especies prioritarias para la conservación en Uruguay. En Vertebrados, moluscos continentales y plantas vasculares (ed. por A. Soutullo, C Clavijo y J.A. Martínez-Lanfranco), pp. 73-90. SNAP/DINAMA/MVOTMA/DICYT-MEC, Montevideo. 
Cortés-Sánchez, M.; A. Morales-Muñiz; M.D. Simón-Vallejo; M.C. LozanoFrancisco;J.L. Vera-Peláez; C. Finlayson; J.Rodríguez-Vidal; A. Delgado-Huertas; F.J. Jiménez-Espejos; F. Martínez-Ruiz; M.A. Martínez-Aguirre; A.J. Pascual-Granged; M.M. Bergadá-Zapata; J.F. Gibaja-Bao; J.A. Riquelme-Cantal; J.A. López-Sáez; M. Rodrigo-Gámiz; S. Sakai; S. Sugisaki; G. Finlayson; D.A. Fa; N.F. Bicho 2011 Earliest known use of marine resources by Neanderthals. PlosOne (6) 9: 1-15.

Díaz, A.

1977 Arqueología de Salto Grande. Secuencia cultural resultante de las investigaciones realizadas en Isla de Arriba y del Medio (Uruguay). V Encuentro de Arqueología del Litoral, pp. 154-174. Ministerio de Educación y Cultura, Montevideo.

Dillehay, $\mathrm{T}$.

1991 Mounds of Social Death: Araucanian Funerary Rites and Political Succesion. En Tombs for the Living: Andean Mortuary Practices (ed. por T. Dillehay), pp. 281-314. Dumbarton Oaks Research Library and Collection, Washington D.C.

Doello-Jurado, M.

1917 Moluscos hallados en un cementerio indígena de la isla Martín García. Physis 3: 224.

1940 Síntesis malacológica. Relaciones 2: 123-144.

d'Orbigny, A.

1835 Voyage dans l'amérique méridionale, Tomo 1. Pitois-Levrault, Paris.

Dupont, C.

2006 La malacofaune de sites mésolithiques et néolithiques de la façade atlantique de la France: Contribution à l'economie et à l'identité culturelle des groupes concernés. British Archaeological Reports - International Series 1571.

Edith, R.

1985 Theoretical and practical considerations in the analysis of anthrosols. En Archaeological Geology (ed. por G. Rapp y J. Gifford), pp.155-190. Yale University Press, New Haven.

Farías, M.

2005 El Guaraní arqueológico meridional: Entre el axioma y la heterodoxia. Tesis Doctoral. PUCRS, RGS.

Farias, M., J. Femeninas, J. Iriarte y A. Florines

1997 Aproximaciones Arqueológicas del área Deltaica del Río Negro (Uruguay). En Jornadas de Antropología de la Cuenca del Plata. Arqueología y Bioantropología, Tomo III: 22-27. Universidad Nacional de Rosario, Rosario.

Figueira, J.H.

1892 Los primitivos habitantes del Uruguay. El Uruguay en la Exposición HistóricaAmericana de Madrid. En Memoria de los trabajos realizados por la Comisión Nacional encargada de organizar los elementos de concurrencia, pp. 121-219. Imprenta Artística Dornaleche y Reyes, Montevideo. 
Figueiro, G; L. Cabrera; J. Lindo; E. K. Mallott; A. Owings; R. S. Malhi; M. Sans

2017 Análisis del genoma mitocondrial de dos individuos inhumados en el sitio arqueológico CG14E01 “Isla Larga” (Rocha, Uruguay). Revista Argentina de Antropología Biológica (19) 1: 1-17.

Foladori, G. y G. Melazzi

2009 La economía de la sociedad capitalista y sus crisis recurrentes. Universidad de la República, Montevideo.

Fontana, M.

1928 Informe sobre la Exploración de un Túmulo Indígena en Punta Chaparro (Colonia-Río Uruguay). Revista Sociedad Amigos de la Arqueología II: 331-349.

1930 Memoria de la excursión científica a Nueva Palmira. Revista Sociedad Amigos de la Arqueología II: 119-181.

1951 Alfarería prehispánica de los paraderos de Nueva Palmira (Depto. de Colonia). Revista Sociedad Amigos de la Arqueología XI: 153-222.

Gascue A.; J. Baeza; M. Fleitas; N. Bortolotto; J. Gómez

2016a Catalogación y contextualización cronológica-estratigráfica de los bienes culturales prehistóricos del Parque Nacional Santa Teresa. Intersecciones en Antropología - Volumen Especial 3: 95-106.

Gascue, A.; D. Loponte; F. Moreno; N. Bortolotto; X. Rodríguez; G. Figueiro; F. Teixeira de Mello; A. Acosta

2016b Tecnología, subsistencia y cronología del sitio El Cerro, departamento de Rio Negro, Uruguay. Anuario de Arqueología 8: 113-139.

Gianotti C.; M. Cacheda; J. Dabezies; I. Capdepont; L. del Puerto; C. Pascual; A. Arcaus; D. Aguirrezabal; S. Alzugaray; P. Fábrega

2007 El Paisaje Arqueológico de las Tierras Bajas uruguayas. Informe a CSIC España, Universidad de la República, Montevideo.

Goso, H. y J. Bossi

1966 Cenozoico. En Geología del Uruguay (ed. por J. Bossi), pp. 259-305. Universidad de la República, Montevideo.

Granada. D.

1957 Diccionario rioplatense razonado. Ministerio de Instrucción Pública y Prevensión Social, Montevideo.

Greslebin, $\mathrm{H}$

1931 La Estructura de los Túmulos Indígenas Prehispánicos del Departamento de Gualeguaychú (Provincia de Entre Ríos, R. Argentina). Revista Sociedad Amigos de la Arqueología V: 6-51.

Guidon, N.

1989 Los sitios de las islas. El sitio Y58. En Misión de Rescate Arqueológico de Salto Grande (ed. por Ministerio de Educación y Cultura), Tomo II, pp. 434-450. Ministerio de Educación y Cultura, Montevideo. 
Hilbert, $\mathrm{K}$.

1991 Aspectos de la arqueología de Uruguay. von Zabern, Manz am Rhein.

Inda, H, L. del Puerto, R. Bracco, C. Castiñeira, I. Capdepont, A. Gascue y J. Baeza 2011 Relación Hombre-Ambiente para la Costa Estuarina y Oceánica del Uruguay durante el Holoceno: Reflexiones y Perspectivas. En El Holoceno en la Zona Costera de Uruguay (ed. por F. García-Rodríguez), pp. 229-260. CSIC-Udelar-Biblioteca plural, Montevideo.

Joordens, J.C.; F. d’Errico; F.P. Wesselingh; S. Munro; J. de Vos; J.Wallinga; Ch. Ankjærgaard; T. Reimann; J.R. Wijbrans; K.F. Kuiper; H.J. Mücher; H. Coqueugniot; V. Prie; I. Joosten; B. van Os; A.S. Schulp; M. Panuel; V. van der Haas; W. Lustenhouwer; J.J. Reijmer; W. Roebroeks

2015 Homo erectus at Trinil on Java used shells for tool production and engraving. Nature 518: 228-244.

Lagiglia, H.A.

2009 Movilidad cultural en el centro-oeste argentino y aledaños. Revista Sociedades de Paisajes Áridos y Semiáridos 1(1): 17-45.

López, R.A.; P.E. Penchaszadeh; S.C. Marcomini

2008 Storm-related stranding sof mollusks on the northeast coast of Buenos Aires, Argentina. Journal of Coastal Research 24(4): 925-935.

López Mazz, J.M.

1994-95. Cabo Polonio: Sitio Arqueológico del Litoral Atlántico Uruguayo. Revista de Arqueología 8 (2): 333-353.

1995a Aproximación al territorio de los constructores de cerritos. En Arqueología en el Uruguay (ed. por M. Consens, J. López Mazz y C. Curbelo), pp. 65-78. Surcos, Montevideo.

1995b El fósil que no guía, y la formación de los sitios costeros. En Arqueología en el Uruguay (ed. por M. Consens, J. López Mazz y C. Curbelo), pp. 92-99. Surcos, Montevideo.

López Mazz, J. y A. Gascue

2007 El Valle del Arroyo Valizas: Estructuras Monticulares y Sitios Superficiales del Litoral Atlántico Uruguayo. Cazadores Recolectores del Cono Sur - Revista de Arqueología 2: 89-103.

López Mazz, J.; A. Gascue; E. Villarmarzo; S. Alzugaray; M. Sotelo; V. De León 2010 Tecnología Lítica de los Humedales del Este: Una Visión Diacrónica. En Mamül Mapú: Pasado y Presente desde la Arqueología Pampeana (ed. por Berón, Luna, Bonomo, Montalvo, Aranda y Carrera), Tomo 2, pp. 285-294. Libros del Espinillo, Ayacucho.

López Mazz, J.; G. Piñeiro; C. Castiñeira; A. Gascue.

1997 Ocupación humana en el litoral atlántico de Uruguay, aproximación paleoambiental al conocimiento de los sitios costeros: sitio "La Esmeralda". En Jornadas de Antropología de la Cuenca del Plata, Tomo III, pp. 28-34. Facultad de Humanidades y Artes-Universidad Nacional de Rosario, Rosario. 
López Mazz, J. y E. Villarmarzo

2009 Explotación intensiva de recursos marinos: el caso del Este de Uruguay. En Arqueología prehistórica uruguaya en el siglo XXI (comp. por J. López Mazz y A. Gascue), pp. 13-26. Biblioteca Nacional-Facultad de Humanidades, Montevideo.

López Mazz, J.; E. Villarmarzo; L. Brum.

2009a Análisis de secciones y plantas arqueológicas del sitio La Esmeralda (Rocha, Uruguay. En Arqueología prehistórica uruguaya en el siglo XXI (comp. por J. López Mazz y A. Gascue), pp.27-38. Biblioteca Nacional-Facultad de Humanidades, Montevideo.

López Mazz, J.; F. Moreno; E. Villarmarzo; A. Gascue

2009b Apuntes para una arqueología costera y del Cabo Polonio. En Arqueología prehistórica uruguaya en el siglo XXI (comp. por J. López Mazz y A. Gascue), pp.39-66. Biblioteca Nacional-Facultad de Humanidades, Montevideo.

Loponte, D.

2008 Arqueología del humedal del Paraná Inferior (Bajíos Ribereños Meridionales). En Arqueología de la Cuenca del Plata (ed. por D. Loponte y A. Acosta), Serie Monográfica, Vol 1, pp. 1-478. Instituto Nacional de Antropología y Pensamiento Latinoamericano, Buenos Aires.

Loponte, D. y A. Acosta

2017 El consumo de moluscos fluviales en sociedades cazadoras-recolectoras y horticultoras del Nordeste de Argentina. En Libro de Resúmenes $X$ Congreso Latinoamericano de Malacología: 111. Ciudad de Piriápolis, Uruguay, 1 al 6 de octubre de 2017.

Loponte, D.; F. Ottalagano; A. Acosta; N. Bortolotto; A. Gascue; D. Viglioco; R. Boretto 2016 Avances en la Arqueología del bajo río Uruguay: el sitio La Yeguada, departamento de Río Negro (Uruguay). Tessituras (4) 1: 8-52.

Maeso, C.

1977 Investigaciones arqueológicas. Imprenta Don Bosco, Montevideo.

Mañosa, C.

1995 Utilización prehistórica de moluscos en Punta de La Coronilla (Rocha, Uruguay). En Arqueología en el Uruguay (ed. por M. Consens, J. López Mazz y C. Curbelo), pp. 116122. Surcos, Montevideo.

Martínez Soler, B.

1959 Conchyliología ethnologica. El uso ornamental y ceremonial de algunas especies de moluscos en territorio argentino, en relación con los desplazamientos étnicos y el comercio indígena prehispánico. Runa IX: 267-322.

Martínez, S. y M. Ubilla

2009 El cuaternario en Uruguay. En Cuencas sedimentarias de Uruguay (ed. por G. Veroslavsky, M. Ubilla. y S. Martínez), pp. 195-227. Dirac-Facultad de Ciencias, Montevideo.

Maruca Sosa, R.

1957 La Nación Charrúa. Letras, Montevideo. 
Meighan C.W.

1980 Los moluscos como restos de alimentos en los sitios arqueológicos. En Ciencia en Arqueología (coord. por D. Brothwell y E. Higgs), pp. 427-434). Fondo de Cultura Económica, México.

Moreno, F.

2005 Estudio arqueofaunístico (vertebrados) del sitio arqueológico La Esmeralda (litoral atlántico uruguayo). Trabajo de investigación de doctorado. Universidad Autónoma de Barcelona, Barcelona.

2014 La gestión de los recursos animales en la prehistoria del Este de Uruguay (4000 años AP Siglo XVI). Tesis doctoral. Universidad Autónoma de Barcelona, Barcelona.

Olazarri, J.

1975 Historia de la malacología en el Uruguay. Edición del autor, Montevideo.

1980 La formación del Embalse de Salto Grande y sus efectos sobre la malacofauna fluvial. En Libro de resúmenes Jornadas de Ciencias Naturales, 1, pp. 21-22. Montevideo.

Ortiz, G. y N. Vargas Rodríguez

2015 Más allá del artefacto. Aproximación al ambiente y estrategias de uso de moluscos en la región del Valle de San Francisco, Jujuy (0 al 500 dc). En Arqueomalacología: abordajes metodológicos y casos de estudio en el Cono Sur (ed. por H. Hammond y M. Angel Zubimendi), pp. 59-77). Fundación de Historia Natural Félix de Azara, Buenos Aires.

Osório Rosa, A.

2006 A importância dos mariscos na subsitência de antigos grupos indígenas no litoral central. Sítios RS-LC-81, 86, 87, 90, 92 e 96. Pesquisas, Antropologia 63:259-288.

Outes, F.

1917 Primer hallazgo arqueológico en la Isla Martín García. Anales de la Sociedad Científica Argentina XXXII: 265-277.

Peralta. J.

1950 El guaraní en la geografía de América. Ediciones Tüpa, Buenos Aires.

Perlman, T.

1980 An Optimun Diet Model, Coast Variability, and Hunter-Gatherer Behaivor. En Advances in Archaeological Method and Theory (ed. por M. Schiffer), 3, pp. 257-309.

Politis, G. y M. Bonomo

2015 Una revisión del Túmulo de Campana. Relaciones de la Sociedad Argentina de Antropología XL (1): 149-181.

Rosa Giordano, M.

2012 Moluscos y conchillas. Una Mirada bajo lupa del material malacológico recuperado por la Misión de Rescate Arqueológico de Salto Grande. Anuario de Arqueología 2011-2012: 207-241.

Ruiz de Montoya, A.

1639 Tesoro de la lengua Guaraní. Imp. Juan Sánchez, Madrid. 
Scarabino, F.

2004a Conservación de la malacofauna uruguaya. Comunicaciones de la Sociedad Malacológica del Uruguay 8 (82/83): 267-273.

2004b Lista sistemática de los Gastropoda dulciacuícolas vivientes de Uruguay. Comunicaciones de la Sociedad Malacologica del Uruguay 8(84/85-86/87): 347-356.

Scarabino, F.; N. Bortolotto; E. Villarmarzo; C. Clavijo; A. Gascue; L. del Puerto; H. Inda; I. Capdepont; C. Gianotti; F. García Rodríguez

2016a Arqueomalacología de la costa platense y atlántica uruguaya: una actualización. En Libro de Resúmenes III Jornadas interdisciplinarias en biodiversidad y ecologí,pp. 55. http:/ / www.cure.edu.uy/sites/default/ files/Libro \%20de \%20resumenes $\% 20 I I \%$ 20JIB E.pdf. (Acceso: 19 de julio, 2018).

Scarabino, F.; G. Martínez; G. Vélez-Rubio; G. Fabiano; A. Martínez; L. Ortega; I. Machado; A. Segura, M. Abreu; C. Crisci; L. Bergamino; B. Yannicelli.

2016b Mortandad masiva de invertebrados marinos bentónicos en la costa atlántica uruguaya (mayo 2016). En Libro de Resúmenes III Jornadas interdisciplinarias en biodiversidad y ecología,pp. 55.

http://www.cure.edu.uy/sites/default/files/Libro\%20de\%20resumenes \%20III\%20JIB E.pdf. (Acceso: 19 de julio, 2018).

Scarabino, F.; J. C. Zaffaroni; A. Carranza; C. Clavijo; M. Nin

2006a Gasterópodos marinos y estuarinos de la costa uruguaya: faunística, distribución, taxonomía y conservación. En Bases para la conservación y el manejo de la costa uruguaya (ed. por R. Menafra, L. Rodríguez-Gallego, F. Scarabino y D. Conde),pp. 143-155. Vida Silvestre Uruguay, Montevideo.

Scarabino, F., J. C. Zaffaroni, C. Clavijo, A. Carranza \& M. Nin

2006b Bivalvos marinos y estuarinos de la costa uruguaya: faunística, distribución, taxonomía y conservación. En Bases para la conservación y el manejo de la costa uruguaya (ed. por R. Menafra, L. Rodríguez-Gallego, F. Scarabino y D. Conde),pp. 157-169. Vida Silvestre Uruguay, Montevideo.

Seijo, C.

1930 Cráneo con fragmentos de un collar. Revista Sociedad Amigos de la Arqueología IV: 183-195.

Soares de Lima. C.

2007 La patria misionera: la civilización jesuítico-guaraní y su influencia en el pensamiento artiguista. Linardi y Riso, Montevideo.

Storch, P.

1997 Conservation of archaeological shell objects. Conservation Notes Texas Memorial Museum 22: 1-6.

Tassé, G.

1989. Excavación II. En Misión de Rescate Arqueológico de Salto Grande (ed. por Ministerio de Educación y Cultura), Tomo II, pp. 450-452. Ministerio de Educación y Cultura, Montevideo. 
Torres, L.M.

1911 Los Primitivos Habitantes del Delta del Paraná. Universidad Nacional de La Plata, La Plata.

Toscano, A.

1987 Noticias sobre la Investigación en Curso en la Desembocadura del Río San Salvador e Inmediaciones. En Primeras Jornadas de Ciencias Antropológicas en Uruguay, pp. 157 - 160. Ministerio de Educación y Cultura, Montevideo.

Trubitt, MB.

2003 The Production and Exchange of Marine Shell Prestige Goods. Journal of Archaeological Research (11) 3: 243-277.

Villarmarzo, E.

2010 Arqueomalacología del sitio La Esmeralda (Rocha, Uruguay). Comunicaciones de la Sociedad Malacológica del Uruguay 9 (93): 215 - 230.

Wagner, G.; K. Hilbert; D. Bandeira; M.C. Tenório; M.M. Okumura

2011Sambaquis (shell mounds) of the Brazilian coast. Quaternary International 239: 5160.

Yesner, D.

1980 Maritime Hunter Gatherer: Ecology and Prehistory. Current Anthropology 2 (6): 727-751.

Zangrando, A.

2009 Is fishing intensification a direct route to hunter-gatherer complexity? A case study from the Beagle Channel region (Tierra del Fuego, southern South America). World Archaeology 41(4): 589-608.

Zorrilla de San Martín, J.

1956 Tabaré. Ministerio de Instrucción Pública y Previsión Social, Montevideo. 